\title{
Mutations in the anticodon stem of tRNA cause accumulation and Met22-dependent decay of pre-tRNA in yeast
}

\author{
MATTHEW J. PAYEA, ALAYNA C. HAUKE, THAREENDRA DE ZOYSA, and ERIC M. PHIZICKY \\ Department of Biochemistry and Biophysics and Center for RNA Biology, University of Rochester School of Medicine, Rochester, \\ New York 14642, USA
}

\begin{abstract}
During tRNA maturation in yeast, aberrant pre-tRNAs are targeted for $3^{\prime}-5^{\prime}$ degradation by the nuclear surveillance pathway, and aberrant mature tRNAs are targeted for $5^{\prime}-3^{\prime}$ degradation by the rapid tRNA decay (RTD) pathway. RTD is catalyzed by the 5' $5^{\prime}$ exonucleases Xrn1 and Rat1, which act on tRNAs with an exposed 5' end due to the lack of certain body modifications or the presence of destabilizing mutations in the acceptor stem, T-stem, or tRNA fold. RTD is inhibited by mutation of MET22, likely due to accumulation of the Met22 substrate adenosine $3^{\prime}, 5^{\prime}$ bis-phosphate, which inhibits 5'-3' exonucleases. Here we provide evidence for a new tRNA quality control pathway in which intron-containing pretRNAs with destabilizing mutations in the anticodon stem are targeted for Met22-dependent pre-tRNA decay (MPD). Multiple SUP4 ${ }_{\text {oc }}$ anticodon stem variants that are subject to MPD each perturb the bulge-helix-bulge structure formed by the anticodon stem-loop and intron, which is important for splicing, resulting in substantial accumulation of end-matured unspliced pre-tRNA as well as pre-tRNA decay. Mutations that restore exon-intron structure commensurately reduce pre-tRNA accumulation and MPD. The MPD pathway can contribute substantially to decay of anticodon stem variants, since pre-tRNA decay is largely suppressed by removal of the intron or by restoration of exon-intron structure, each also resulting in increased tRNA levels. The MPD pathway is general as it extends to variants of tRNA ${ }^{\text {Tyr(GUA) }}$ and tRNA $^{\text {Ser(CGA) }}$. These results demonstrate that the integrity of the anticodon stem-loop and the efficiency of tRNA splicing are monitored by a quality control pathway.
\end{abstract}

Keywords: rapid tRNA decay; pre-tRNA; tRNA splicing; S. cerevisiae; MPD

\section{INTRODUCTION}

In all organisms, the central role of tRNAs in decoding mRNA during translation places restrictions on the properties of tRNA. tRNAs must be selective in charging by their cognate synthetase (Giege et al. 1998; Fechter et al. 2000; Kermgard et al. 2017), and in their anticodon-codon interactions during decoding (Murphy et al. 2004; Agris et al. 2007; Demeshkina et al. 2012; Rozov et al. 2016; Loveland et al. 2017); they must adopt a conserved structure to uniformly participate in translation, with sufficient flexibility for accommodation and passage through the ribosome (Kim et al. 1974; Marck and Grosjean 2002; Valle et al. 2003; Schmeing et al. 2009; Giege et al. 2012; Ramrath et al. 2013; Zhou et al. 2013, 2014); and they must be stable enough to have long half-lives, enabling participation in multiple rounds of translation (Kadaba

Corresponding author: eric_phizicky@urmc.rochester.edu

Article is online at http://www.rnajournal.org/cgi/doi/10.1261/rna. 073155.119. et al. 2004; Alexandrov et al. 2006; Chernyakov et al. 2008; Gudipati et al. 2012).

tRNAs undergo a highly complex maturation process. In the yeast Saccharomyces cerevisiae and other eukaryotes, tRNAs are transcribed by Pol III as pre-tRNAs with a $5^{\prime}$ leader, a $3^{\prime}$ trailer, and in some cases an intron, all of which must be removed before the tRNA can participate in translation (Hopper 2013). Although introns only occur in a subset of tRNAs in different organisms, they are found ubiquitously in eukaryotes, and tRNA splicing is essential in all eukaryotes examined. In vertebrates and higher eukaryotes, the end trimming and splicing steps are completed in the nucleus (Nishikura and De Robertis 1981; Lund and Dahlberg 1998). However, in S. cerevisiae and Schizosaccharomyces pombe, end-processed intron-containing pre-tRNAs are

(C) 2020 Payea et al. This article is distributed exclusively by the RNA Society for the first 12 months after the full-issue publication date (see http://rnajournal.cshlp.org/site/misc/terms.xhtml). After 12 months, it is available under a Creative Commons License (Attribution-NonCommercial 4.0 International), as described at http:// creativecommons.org/licenses/by-nc/4.0/. 
exported from the nucleus after end trimming and then spliced in the cytoplasm, initiated by the splicing endonuclease (SEN) complex on the surface of the mitochondria (Trotta et al. 1997; Yoshihisa et al. 2003, 2007; Wan and Hopper 2018). In addition, an extensive set of modifications are added to the tRNA throughout the course of processing (Etcheverry et al. 1979; Peebles et al. 1979; Nishikura and De Robertis 1981), including a final set of modifications that occur in the anticodon loop after splicing, after the subsequent retrograde import of spliced tRNAs into the nucleus, or after re-export of the spliced tRNAs back to the cytoplasm (Shaheen and Hopper 2005; Takano et al. 2005; Murthi et al. 2010; Ohira and Suzuki 2011).

The necessity for proper tRNA maturation and function is evident from the numerous human diseases associated with incorrectly processed tRNAs. Hypomodification of tRNAs, caused by mutation of either the modifying enzyme or the tRNA itself, can result in numerous mitochondrial and neurological diseases (Yarham et al. 2010, 2014; Suzuki et al. 2011; Gillis et al. 2014; Karlsborn et al. 2014; Torres et al. 2014; Guy et al. 2015; Shaheen et al. 2016; de Brouwer et al. 2018); mutations in the human SEN complex responsible for the cleavage step of tRNA splicing can cause pontocerebellar hypoplasia and neurodegeneration (Budde et al. 2008; Bierhals et al. 2013; Breuss et al. 2016); and mutations in the aminoacyl tRNA synthetases can cause a host of neurological diseases (Lee et al. 2006; Boczonadi et al. 2018).

In S. cerevisiae, the fidelity of tRNA maturation is monitored both as pre-tRNA, by the nuclear surveillance pathway, and as mature tRNA, by the rapid tRNA decay (RTD) pathway. The nuclear surveillance pathway acts through the TRAMP complex and the nuclear exosome to degrade pre-tRNA ${ }_{i}{ }^{\text {Met }}$ lacking the 1-methyladenosine $\left(m^{1} \mathrm{~A}\right)$ modification (Kadaba et al. 2004, 2006; LaCava et al. 2005; Vaňáčová et al. 2005), and may also degrade as much as half of the total transcribed pre-tRNA, likely due to transcription errors or folding defects (Gudipati et al. 2012). After maturation, tRNAs are subject to quality control by the RTD pathway, which degrades certain hypomodified tRNAs and tRNAs with destabilizing mutations, using the 5'-3' exonucleases Rat1 in the nucleus, and Xrn1 in the cytoplasm (Alexandrov et al. 2006; Chernyakov et al. 2008; Whipple et al. 2011; Dewe et al. 2012; Kramer and Hopper 2013; Guy et al. 2014; Payea et al. 2018). The RTD pathway targets tRNAs due to exposure of the $5^{\prime}$ end arising from reduced stability of the acceptor/ T-stem, as shown by both structure probing and Xrn1 assay of hypomodified tRNA ${ }^{\text {Ser(CGA) }}$ [tS(CGA)] variants, and by Xrn1 assay of hypomodified tV(AAC) (Whipple et al. 2011). The degradation of all identified substrates of the RTD pathway is inhibited genetically and biochemically by a met22 $\Delta$ mutation (Chernyakov et al. 2008; Dewe et al. 2012; Guy et al. 2014; Payea et al. 2018). The sup- pression of RTD by a met $22 \Delta$ mutation is likely an indirect effect due to elevated levels of the Met22 substrate adenosine 3', 5' bisphosphate (pAp) (Murguía et al. 1996), which inhibits both Xrn1 and Rat1 in vitro and in vivo (Dichtl et al. 1997; Yun et al. 2018). There is also evidence that the RTD pathway may be conserved in humans, since Xrn1 and the human Rat1 ortholog Xrn2 can mediate the decay of tRNA ${ }_{i}^{\text {Met }}$ after heat shock (Watanabe et al. 2013).

As the RTD pathway targets substrates due to $5^{\prime}$ end exposure (Whipple et al. 2011), it was surprising to find from high-throughput analysis of variants of the suppressor SUP4 ${ }_{\text {oc }}$ (tY(GUA) with a UUA anticodon) that met22 2 mutants prevented the decay of numerous variants with destabilizing mutations in the anticodon stem (Guy et al. 2014; Payea et al. 2018). Although the Met22-dependent decay of anticodon stem variants implicated the RTD pathway, anticodon stem mutations were not expected to significantly destabilize the $5^{\prime}$ end to trigger RTD, as there is little interaction of nucleotides in this stem with other parts of the tRNA body, other than limited stacking of the anticodon stem with the D-stem (Ladner et al. 1975; Westhof et al. 1985).

Here we describe a new Met22-dependent pre-tRNA decay pathway that, unlike RTD, targets end-matured unspliced pre-tRNA variants with mutations in the anticodon stem-loop that perturb exon-intron structure. We first show that the Met22-dependent decay of anticodon stem SUP $4_{o c}$ variants is quantitatively equivalent to that of acceptor stem variants in vivo, despite their reduced sensitivity to $5^{\prime}-3^{\prime}$ exonucleases in vitro. We explain this discrepancy by showing that these anticodon stem variants have a defect in pre-tRNA maturation, which causes an accumulation of end-matured unspliced pre-tRNA that is targeted for decay. We show that this Met22-dependent pretRNA decay (MPD) is due to the perturbed secondary structure in the region comprising the anticodon stemloop and the intron, and that MPD contributes significantly to overall decay of anticodon stem variants. We further find that MPD is a general pathway of quality control for pretRNA since it also occurs in $\mathrm{tY}(\mathrm{GUA})$ and $\mathrm{tS}(\mathrm{CGA})$ variants. These results document for the first time that the tRNA exon-intron structure is subject to quality control in yeast. As introns are found in many tRNAs throughout eukaryotes, MPD may be conserved in higher eukaryotes as well.

\section{RESULTS}

\section{Anticodon stem variants are susceptible to Met22- dependent tRNA decay in vivo, but not to RTD exonucleases in vitro}

Because of our finding that SUP4 ${ }_{o c}$ anticodon stem variants could provoke Met22-dependent tRNA decay in the absence of known mechanisms by which they could significantly destabilize the tRNA 5' end (Guy et al. 2014), we 
quantitatively compared the decay of anticodon stem and acceptor stem SUP4 $4_{o c}$ variant substrates. We examined the tRNA levels of biological triplicates for three acceptor stem variants, seven anticodon stem variants, and one anticodon loop variant (Fig. 1A). We used poison primer extension to directly compare mature tRNA levels of SUP4 $4_{o c}$ variants as a percentage of endogenous $\mathrm{TY}(\mathrm{GUA})$ in a MET22 ${ }^{+}$strain and in a met22 $\Delta$ strain, in which the $5^{\prime}-3^{\prime}$ exonucleases of the RTD pathway are inhibited, and then calculated the ratio of these two values (met22L/ MET22 ${ }^{+}$) to obtain a tRNA decay ratio, previously called the RTD ratio (Guy et al. 2014; Payea et al. 2018).

Consistent with previous findings, we found that a met22 $\Delta$ mutation resulted in a large quantitative increase in the tRNA levels for all 11 tested variants, and thus a substantial tRNA decay ratio (Fig. 1B,C; Supplemental Fig. S1). Seven variants had a tRNA decay ratio greater than four $\left(C_{5} \mathrm{U}, \mathrm{A}_{29} \mathrm{U}, \mathrm{G}_{30} \mathrm{~A}, \mathrm{C}_{40} \mathrm{U}, \mathrm{U}_{41} \mathrm{~A}, \mathrm{U}_{42} \mathrm{~A}, \mathrm{G}_{69} \mathrm{C}\right)$, and four had a ratio between two and four $\left(\mathrm{U}_{2} \mathrm{C}, \mathrm{A}_{28} \mathrm{U}, \mathrm{A}_{31} \mathrm{U}, \mathrm{C}_{32} \mathrm{~A}\right)$, indicating that they were subject to substantial Met22-dependent decay. Moreover, the average tRNA decay ratio of 5.4 for anticodon stem variants was at least as large as the average decay ratio of 4.4 for acceptor stem variants. This finding emphasizes the unusual nature of anticodon stem substrates, in that despite their predicted inability to substantially increase the exposure of the $5^{\prime}$ end to exonucleases, they are subject to Met22-dependent decay in vivo as effectively as mutations in the acceptor stem.

To directly determine if the similar in vivo tRNA decay ratios of anticodon stem variants and acceptor stem variants were due to similar $5^{\prime}$ end accessibility, we measured $5^{\prime}-3^{\prime}$ exonuclease activity in vitro on a set of SUP $4_{o c}$ variants, as we had previously done with $\mathrm{tS}(\mathrm{CGA})$ variants and $\mathrm{Xrn} 1$ (Whipple et al. 2011). To assay decay, we used a biotinylated oligomer to purify SUP4 ${ }_{o c}$ variants together with endogenous $\mathrm{T} Y(G \cup A)$, incubated the tRNAs with purified preparations of Xrn1 or Rat1/Rai1 complex (Xue et al. 2000; Xiang et al. 2009), and assayed decay by poison primer extension, using the endogenous purified tY (GUA) as a control (Payea et al. 2015).

With Xrn1, we found that the $\mathrm{U}_{2} \mathrm{C}$ acceptor stem variant was highly susceptible to decay at $37^{\circ} \mathrm{C}$, whereas the $A_{29} \mathrm{U}$ and $\mathrm{A}_{31} \mathrm{U}$ anticodon stem variants were nearly as resistant as the negative control SUP4 ${ }_{o c}$ (Fig. 1D,E; Supplemental Fig. S2A). This assay was done at $37^{\circ} \mathrm{C}$, as many known RTD substrates are more sensitive to decay in vivo at high temperature (Chernyakov et al. 2008; Payea et al. 2018). At $30^{\circ} \mathrm{C}$, at which tRNAs are expected to be less prone to decay, we still observed substantial sensitivity of the $\mathrm{U}_{2} \mathrm{C}$ variant to $\mathrm{Xrn} 1$, whereas the anticodon stem variants were both highly resistant (Supplemental Fig. S2B-D).

We performed similar experiments with the purified Rat1/Rai1 complex at $37^{\circ} \mathrm{C}$ and again observed that anticodon stem variants were more resistant to decay than ac- ceptor stem variants. The SUP4 $4_{o c}$ acceptor stem $\mathrm{U}_{2} \mathrm{C}$ and $\mathrm{C}_{5} \mathrm{U}$ variants were highly susceptible to decay over a range of Rat1/Rai1 concentrations, whereas the $A_{31} U$ anticodon stem variant was highly resistant, and the $\mathrm{A}_{29} \mathrm{U}$ and $\mathrm{C}_{40} \mathrm{U}$ anticodon stem variants were moderately resistant (Fig. 1F; Supplemental Figs. S3, S4).

The finding that anticodon stem variants were uniformly more resistant in vitro to $5^{\prime}-3^{\prime}$ exonucleases than acceptor stem variants is consistent with our expectation that a destabilized anticodon stem would have a limited effect on $5^{\prime}$ end exposure, but is seemingly contradictory to our in vivo data showing that anticodon stem and acceptor stem variants were similarly sensitive to Met22-dependent tRNA decay. The discrepancy between our in vitro and in vivo data implied that the degradation of anticodon stem variants might have an additional aspect in vivo that we were not able to account for in vitro.

\section{Anticodon stem variants accumulate pre-tRNA that is targeted for decay}

We considered that the tRNA decay ratio of anticodon stem variants measured in vivo might actually be the sum of conventional decay of mature tRNA by the RTD pathway and decay of the pre-tRNA by a separate Met22-dependent pathway. As it was previously shown that anticodon stem variants of both tY(GUA) and $\mathrm{tS}(\mathrm{CGA})$ could impair tRNA maturation (Nishikura et al. 1982; Yoo and Wolin 1997), it seemed reasonable that SUP4 ${ }_{o c}$ anticodon stem variants might accumulate pre-tRNA that was subject to decay.

To determine if the pre-tRNAs of anticodon stem variants were also subject to Met22-dependent decay, we used poison primer extension to look for increased pretRNA in a met22 $\Delta$ strain relative to a MET22 ${ }^{+}$strain. The primer for this experiment extended from $\mathrm{N}_{51}$ in the $3^{\prime}$ tRNA exon through to the most $5^{\prime}$ residue of the intron $\left(\operatorname{In}_{1}\right)$, and would detect any of the unspliced precursors in the tRNA maturation pathway (Fig. 2A).

We found evidence for substantial Met22-dependent decay of pre-tRNA in our set of anticodon stem variants. Initial experiments showed that for both the SUP4 ${ }_{o c} A_{29} \mathrm{U}$ and $\mathrm{U}_{41} \mathrm{~A}$ anticodon stem variants in a MET22 ${ }^{+}$strain, there was a large accumulation of pre-tRNA [107\% and $66.7 \%$ of the endogenous pre-tY(GUA)] relative to that for wild type (WT) pre-SUP4 ${ }_{\text {oc }}(14.7 \%)$, an increase of 7.3fold and 4.5-fold, respectively. Moreover, the pre-tRNA levels of the SUP $4_{o c} A_{29} \mathrm{U}$ and $\mathrm{U}_{41} \mathrm{~A}$ anticodon stem variants were further increased in a met22 $\Delta$ strain (16.2-fold and 8.6-fold, relative to WT pre-SUP4 ${ }_{o d}$, resulting in pretRNA decay ratios (pre-tRNA in met22 2 /pre-tRNA in $\mathrm{MET}_{22}{ }^{+}$) of 2.3 and 1.9 , respectively (Fig. 2B). In contrast, although there was a modest relative accumulation of pretRNA for the SUP4 ${ }_{o c} \mathrm{C}_{5} \mathrm{U}$ acceptor stem variant (2.4-fold), 
A

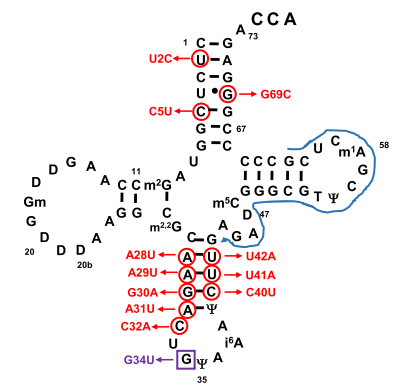

B

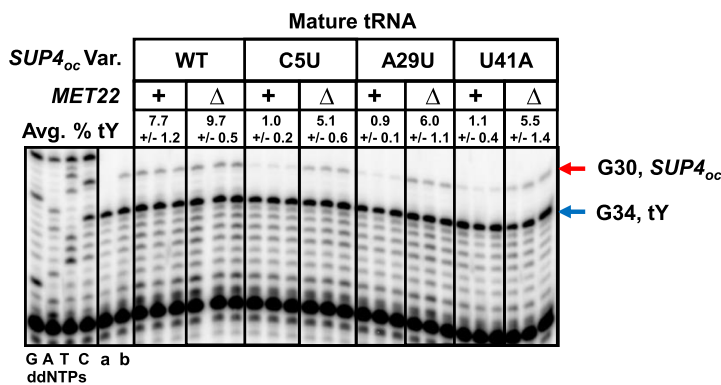

C

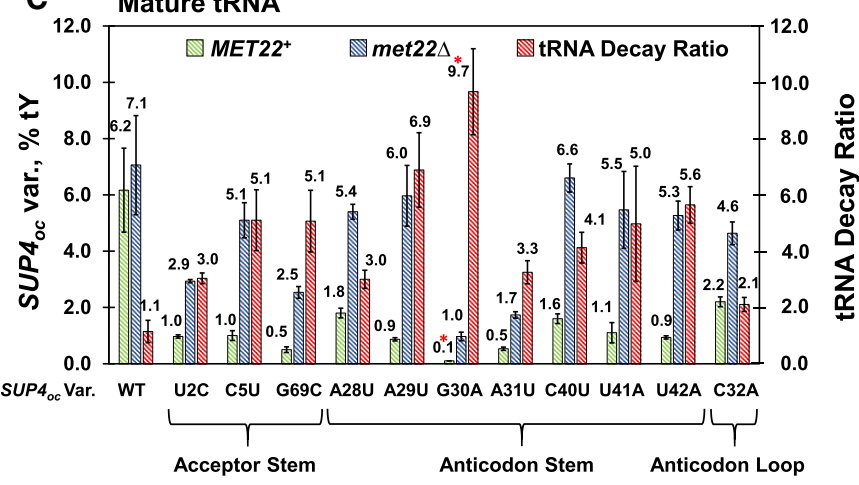

D Xrn1 $37^{\circ} \mathrm{C}$

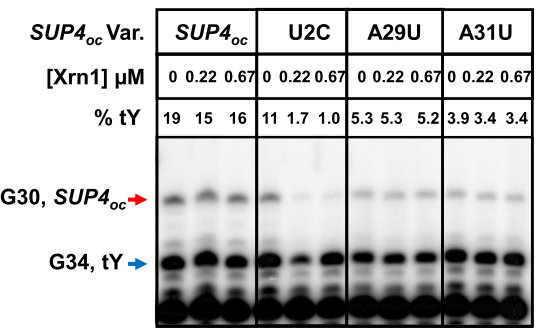

E

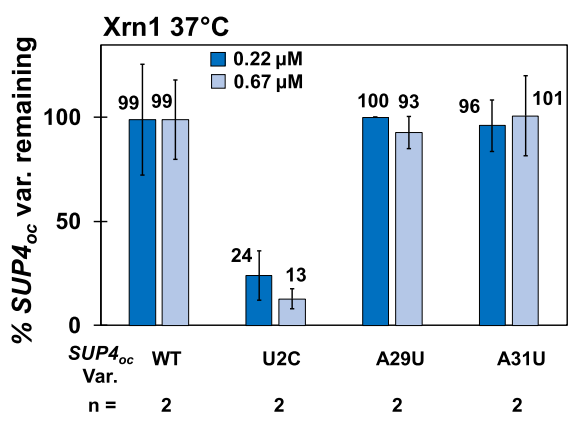

F

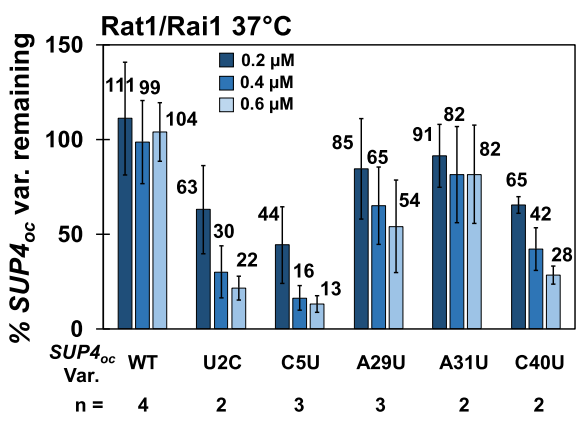

FIGURE 1. The tRNA decay ratio of anticodon stem SUP4 ${ }_{o c}$ variants is quantitatively similar to that of acceptor stem variants. (A) Schematic of $S U P 4_{o c}$ secondary structure and variants examined. The secondary structure of $\mathrm{tY}(\mathrm{GUA})$ is shown, along with the $\mathrm{G}_{34} \mathrm{U}$ ochre mutation of $S U P 4_{o c}$ (purple); variants examined (red); and the P7 primer used for poison primer extension analysis of mature tRNA (blue line). (B) Poison primer extension analysis of SUP4 $4_{o c}$ anticodon stem and acceptor stem variants. Strains containing an integrated copy of a SUP4 $4_{o c}$ tRNA variant as indicated were grown at $28^{\circ} \mathrm{C}$ to mid-log phase, and bulk RNA was analyzed by poison primer extension with the P7 primer (complementary to nt $62-$ 43 ) in the presence of ddCTP, producing a stop at $\mathrm{G}_{34}$ for endogenous $\mathrm{Y}$ (GUA) (blue arrow) and at $\mathrm{G}_{30}$ for integrated $S U P 4_{o c}$ variants (red arrow), visualized after electrophoresis. A sequencing ladder is shown at the left. To confirm that all the measured $\mathrm{G}_{30}$ signal is from $\mathrm{SUP}_{\text {oc }}$ variants, bulk RNA was also analyzed from a strain containing no SUP4 $4_{o c}$ variant (lane a) and an intronless SUP4 $4_{o c}$ variant (lane b). SUP4 $4_{o c}$ variants were quantified as a percentage of the endogenous $\mathrm{TY}(\mathrm{GUA})(\% \mathrm{tY})$, and an average value was determined for each $S U P 4_{o c}$ variant from the triplicate samples in each genetic background (Avg. \% tY). As detailed in Materials and Methods, data obtained from variants measured at the same time as their controls are highly consistent. (C) SUP4 ${ }_{o c}$ anticodon stem and acceptor stem variants have increased tRNA levels in met22 2 relative to MET22 ${ }^{+}$. Bar chart depicting average $\% t Y$ values and tRNA decay ratios with associated standard deviations for variants analyzed. tRNA levels are indicated by diagonal hatching for MET22 ${ }^{+}$(green); and for met22 (blue); tRNA decay ratios are indicated by red diagonal hatching. For $S U P 4_{o c} n=12$ derived from four different measurements of biological triplicates analyzed on different days; for all other variants, $n=3$ for biological triplicates analyzed in the same experiment on the same day. The depicted error for tRNA decay ratios represents propagated error for the quotient of met22 $/$ $M E T 22^{+}$average \% $\mathrm{tY}$ values. The red asterisks above the $\mathrm{G}_{30} \mathrm{~A}$ data for MET22 ${ }^{+}$levels and tRNA decay ratio indicate that tRNA levels in MET22 ${ }^{+}$ were at or below background, and therefore those values could not be accurately measured. (D) Analysis of in vitro degradation of purified SUP4 ${ }_{o c}$ variants by purified $\mathrm{Xrn}_{\mathrm{rn}}$ at $37^{\circ} \mathrm{C}$. Purified mixtures of $S U P 4_{o c}$ variants and $\mathrm{tY}(\mathrm{GUA})$ were incubated with purified Xrn1 at the indicated concentrations at $37^{\circ} \mathrm{C}$ for $20 \mathrm{~min}$. Reaction products were analyzed by measuring the remaining SUP4 $4_{o c}$ variant tRNA relative to $\mathrm{t} Y(\mathrm{GUA})$ by using poison primer extension analysis with primer P5 (nt 57-37) in the presence of ddCTP, producing a stop at $\mathrm{G}_{34}$ for endogenous $\mathrm{Y}$ (GUA) (blue arrow) and at $\mathrm{G}_{30}$ for $S U P 4_{o c}$ variants (red arrow). (E) Anticodon stem variants are more resistant than an acceptor stem variant to in vitro degradation by $\mathrm{Xrn} 1$ at $37^{\circ} \mathrm{C}$. The chart shows the quantification of poison primer extensions used in the analysis of in vitro digests of SUP4 ${ }_{o c}$ variants with purified Xrn 1 at $37^{\circ} \mathrm{C}$, performed at two different concentrations $(n=2$, replicates assayed on different days). ( $F)$ Anticodon stem variants are more resistant than acceptor stem variants to in vitro degradation by Rat $1 /$ Rai 1 at $37^{\circ} \mathrm{C}$. The bar chart shows the quantification of poison primer extension analysis of in vitro digests of purified $S U P 4_{o c}$ variants with purified Rat $1 /$ Rai1 complex at $37^{\circ} \mathrm{C}$, performed at three different concentrations as indicated, with two to four replicates as indicated, conducted on different days. 
A

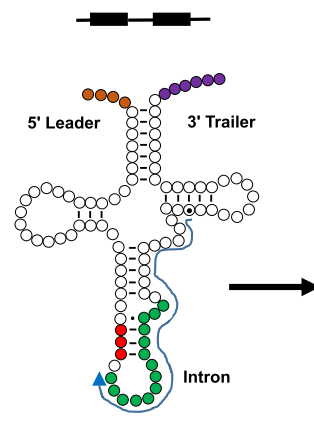

C

$$
\text { C }
$$

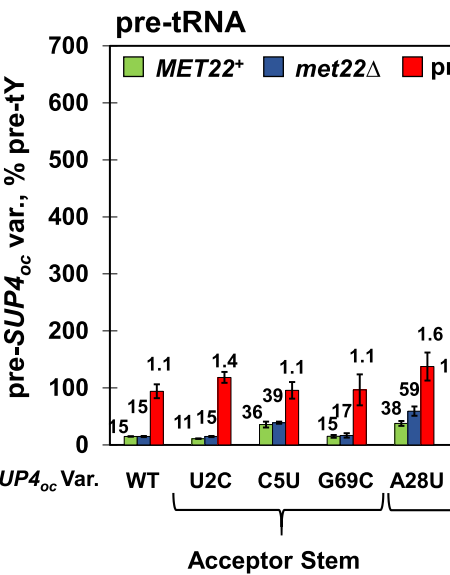

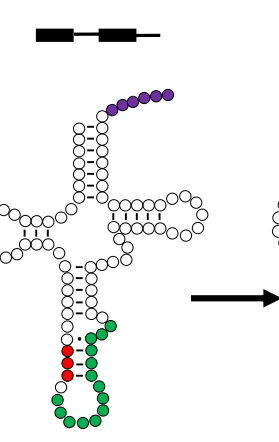

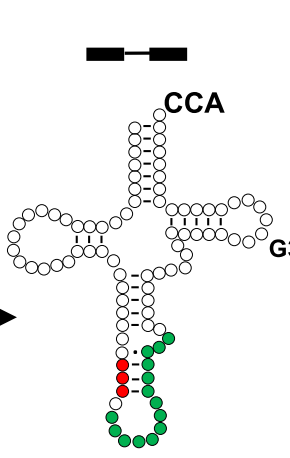

B

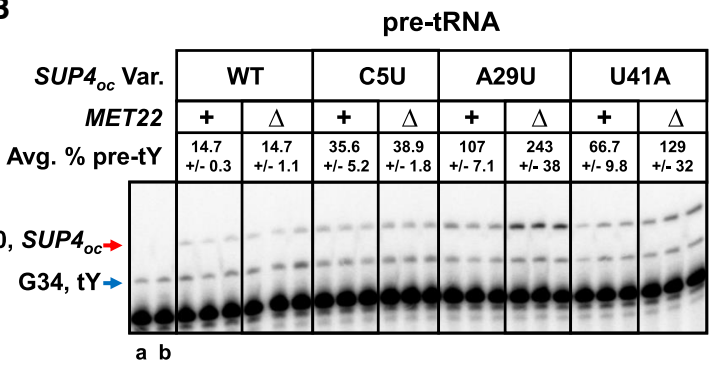

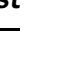


had substantially increased levels in the met22 $\Delta$ strain compared to the MET22 ${ }^{+}$strain, whereas the levels of the other pre-tRNA species were unchanged in the two strains, indicating that the end-matured unspliced pretRNA species was the target for the Met22-dependent decay (Fig. 2D). We observed the same results for the SUP4 $G_{30} A$ and $A_{31} U$ anticodon stem variants (Supplemental Fig. S6). Thus, it is a general property that SUP4 ${ }_{o c}$ anticodon stem variants subject to Met22-dependent tRNA decay have substantially increased levels of end-matured unspliced pre-tRNA in MET22 ${ }^{+}$and met $22 \Delta$ strains, and have substantial pre-tRNA decay ratios, now referred to as Met22-dependent pre-tRNA decay (MPD). This finding offers a simple explanation for the discrepancy between the similar tRNA decay ratios of anticodon stem and acceptor stem variants in vivo, and the relative resistance of anticodon stem variants to $5^{\prime}-3^{\prime}$ exonucleases in vitro, since only mature tRNA decay was accounted for in our in vitro assays.

\section{Destabilization of anticodon-intron base-pairing causes pre-tRNA accumulation and decay}

The large accumulation of end-matured unspliced pretRNA associated with MPD of SUP4 ${ }_{o c}$ anticodon stem variants suggested that perturbation of the pre-tRNA structure might in some way inhibit maturation to trigger decay. In intron-containing pre-tRNAs, the anticodon forms part of a central helix with residues in the intron, surrounded by two bulges that comprise a bulge-helix-bulge region, which is recognized and cleaved by the SEN complex in the first step of splicing (Ogden et al. 1984; Swerdlow and Guthrie 1984; Lee and Knapp 1985; Fruscoloni et al. 2001; Xue et al. 2006). This characteristic pre-tRNA structure of the anticodon stem-loop and intron is predicted to be relatively unstable in pre-tY(GUA) (Reuter and Mathews 2010), which has only four base pairs in the central helix between the anticodon region and the intron (Fig. 3A); moreover, the $\mathrm{G}_{34} \mathrm{U}$ ochre mutation of SUP4 ${ }_{o c}$ is predicted to destabilize the anticodon-intron pairing by disrupting the normal $G_{34}$ pairing with intron residue $\ln _{11}$, and to alter the pre-tRNA structure in the region. Thus, it seemed plausible that the $\mathrm{G}_{34} \mathrm{U}$ ochre mutation could be contributing to the accumulation of SUP4 ${ }_{o c}$ pre-tRNAs observed in some of the anticodon stem RTD variants.

We tested the importance of exon-intron structure in pre-tRNA decay of three SUP4 $4_{o c}$ variants $\left(A_{29} U, G_{30} A\right.$, and $A_{31} U$ ) by constructing $t Y(G \cup A)$ derivatives, bearing a native GUA anticodon instead of the $\mathrm{G}_{34} \mathrm{U}$ mutation in SUP4 $4_{o c}$ and comparing pre-tRNA levels and pre-tRNA decay ratios to the corresponding SUP4 ${ }_{o c}$ variants by poison primer extension. The pre-tRNA decay ratios were dramatically reduced in the $t Y(G \cup A) A_{29} U$ and $A_{31} U$ anticodon stem variants compared to the corresponding SUP4 $4_{O C}$ variants, from 2.4 to 1.3 for the $A_{29} U$ variant, and from 2.0 to
1.1 for the $A_{31} U$ variant (Fig. 3B, C; Supplemental Fig. S7A). Moreover, pre-tRNA accumulation in the met22 $\Delta$ strain was also dramatically reduced in the $t Y(G U A)$ variants compared to the SUP4 ${ }_{o c}$ variants, 3.3-fold for the $A_{29} U$ variant [from $146 \%$ to $44 \%$ of pre-tY(GUA)] and 4.1 fold in the $A_{31} U$ variant. Furthermore, for these two variants, pretRNA decay comprises a major component of their overall tRNA decay, since the dramatic reduction in pre-tRNA decay ratios for the $\mathrm{tY}(\mathrm{GUA}) \mathrm{A}_{29} \mathrm{U}$ and $\mathrm{A}_{31} \mathrm{U}$ variants (relative to the corresponding SUP4 ${ }_{o c}$ variants) was matched by a similar reduction in their tRNA decay ratios (Fig. 3D; Supplemental Fig. S8).

To further examine the extent that perturbation of the pre-tRNA structure could provoke MPD, we generated a variant we called SUP4 ${ }_{C A C}$ in which the anticodon of $t Y$ (GUA) was mutated to prevent any substantial pairing between the intron and exon, but the tRNA was otherwise WT. We found that SUP4 ${ }_{\text {CAC }}$ significantly accumulated pre-tRNA in a MET22 ${ }^{+}$strain $(26.9 \%$ of endogenous pretY, compared to $16.4 \%$ for SUP4 ${ }_{o c}$ ) and further accumulated pre-tRNA in a met $22 \Delta$ strain, leading to a pre-tRNA decay ratio of 1.6 (Supplemental Fig. S9), similar to the ratios obtained for the SUP4 ${ }_{o c} A_{28} U$ and $U_{42} A$ anticodon stem variants. This result, and the results from the tY(GUA) $A_{29} U$ and $A_{31} U$ variants, are consistent with a model in which pre-tRNA decay is driven by pre-tRNA accumulation, which is in turn due to perturbation of the pre-tRNA structure that is important for splicing.

In contrast to the substantial reduction of pre-tRNA decay in the $\operatorname{tY}(G \cup A) A_{29} U$ and $A_{31} U$ variants relative to the corresponding SUP4 $4_{o c}$ variants, the pre-tRNA decay ratio was only modestly reduced for the $\mathrm{t} Y(G \cup A) G_{30} A$ variant, compared to the SUP4 ${ }_{o c} G_{30} A$ variant (from 3.3 to 2.4), and the pre-tRNA accumulation was only slightly reduced in the met22 $\Delta$ strain for the $\mathrm{TY}(\mathrm{GUA}) \mathrm{G}_{30} \mathrm{~A}$ variant, relative to the SUP4 ${ }_{o c} \mathrm{G}_{30} \mathrm{~A}$ variant [1.2-fold, from $148 \%$ to $124 \%$ tY (GUA)] (Fig. 3C; Supplemental Fig. S7B). The persistence of the $\mathrm{G}_{30} A$ mutation in causing substantial pre-tRNA decay and pre-tRNA accumulation with either a native GUA anticodon or an ochre anticodon is consistent with the greater predicted disruption in pre-tRNA structure caused by the $G_{30} A$ mutation, compared to either the $A_{29} U$ or $A_{31} \cup$ mutations (Reuter and Mathews 2010). This result also emphasizes that substantial amounts of pre-tRNA decay can occur in anticodon stem $\mathrm{tY}(\mathrm{GUA})$ variants with a natural GUA anticodon, accompanied by comparably large accumulations of pre-tRNA in the met22 $\Delta$ strain, and large tRNA decay ratios (Supplemental Fig. S10).

We further tested the importance of anticodon-intron pairing in tRNA decay by making a compensatory mutation at $\mathrm{In}_{11}$ to restore pairing with residue $U_{34}$ of $S U P 4_{O C}$ (making a SUP4 $4_{o c}$ variant denoted as SUP4 ${ }_{o c} \ln { }^{\circ}$ ), albeit with a U-A pair instead of the native G-C pair (Fig. 3A). We found that the resulting SUP4 ${ }_{o c} \ln ^{\circ C} A_{29} U$ and SUP4 $\mathrm{In}^{\mathrm{OC}} \mathrm{A}_{31} \mathrm{U}$ variants each had the anticipated reduction in 
A

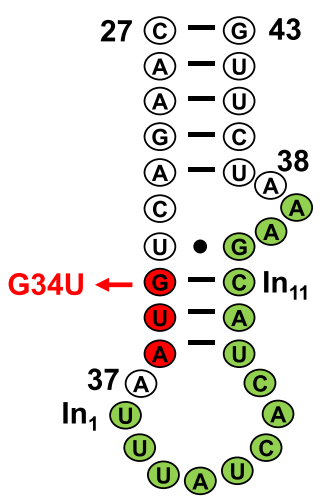

B

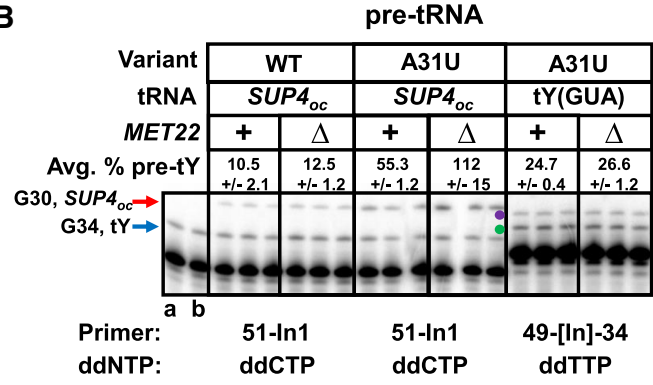

C

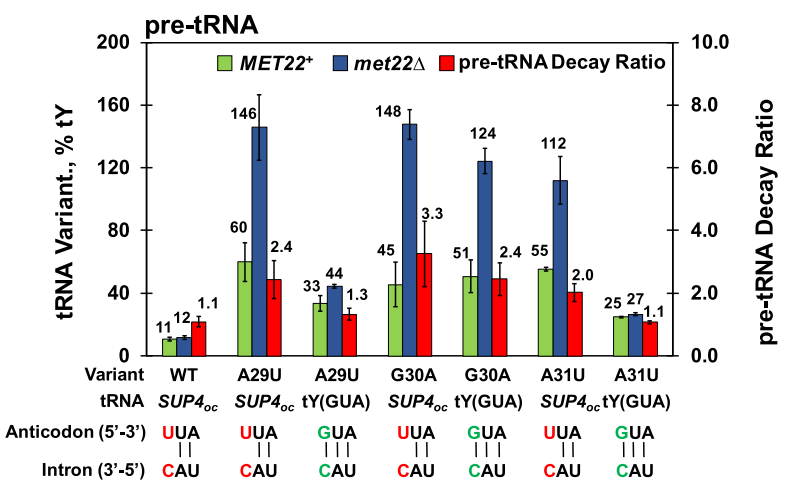

D

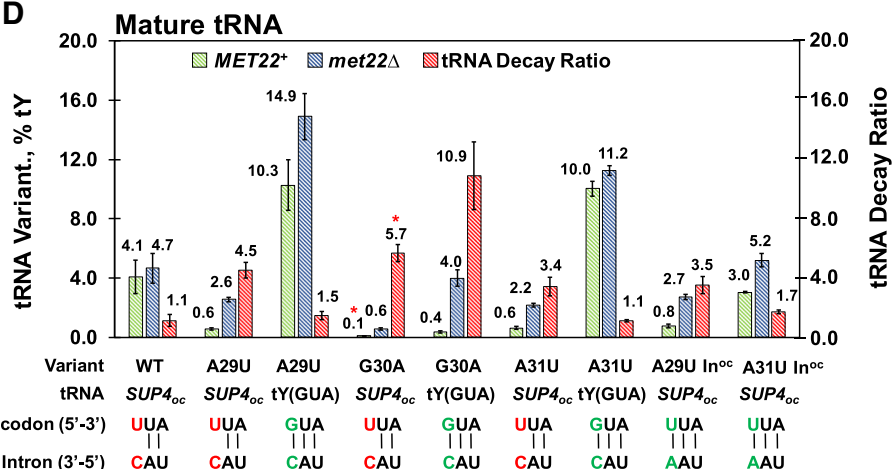

FIGURE 3. Anticodon-intron base-pairing has a substantial effect on pre-tRNA accumulation and Met22-dependent pre-tRNA decay. (A) Schematic of the structure of the anticodon stem-loop and intron of pre-tY(GUA). Nucleotides $\mathrm{N}_{27}-\mathrm{N}_{43}$ of the anticodon stem-loop are shown, as well as the intron (residues $\ln _{1}$ to $\ln _{14}$ ) arranged in the bulge-helix-bulge secondary structure common to substrates of the SEN complex. Anticodon, red; intron, green. The $\mathrm{G}_{34} \mathrm{U}$ mutation of $S U P 4_{o c}$ is indicated in red. (B) Analysis of Met22-dependent pre-tRNA decay of the $S_{S U P} 4_{o c} A_{31} U$ and $T Y(G U A) A_{31} U$ variants. Variants as indicated were analyzed for pre-tRNA levels by poison primer extension as described in Figure 2B. Primer MP $497\left(51-\ln _{1}\right)$ and ddCTP were used for the analysis of SUP4 $4_{c}$ variants, and Primer MP 538 (49-[In]-34) and ddTTP were used for analysis of $\mathrm{TY}\left(\mathrm{GUA}\right.$ ) variants, producing stops at $\mathrm{A}_{31}$ for endogenous pre-tY(GUA) (green dot) and at $A_{29}$ for SUP4 ${ }_{o c} A_{31} U$ pre-tRNA (purple dot). (C) Restoration of anticodon-intron base-pairing suppresses MPD for the SUP4 $4_{o c} A_{29} \cup$ and $A_{31} U$ variants, but not the $S U P 4_{o c} G_{30} A$ variant. Bar chart of \% pre-tY levels and pre-tRNA decay ratios for variants that have either mismatches or pairing between $N_{34}$ and $\ln _{11}$ as indicated in the Anticodon $\left(5^{\prime}-3^{\prime}\right)$ and Intron $\left(3^{\prime}-5^{\prime}\right)$ rows; no pairing, red text and no dash; pairing, green text with dash. (D) The suppression of MPD by the restoration of anticodon-intron pairing also suppresses tRNA decay ratios. Bar graph of \% tY levels and tRNA decay ratios for variants as indicated. Symbols and pairings as in $C$. The red asterisks above the $G_{30} A$ data for MET22 levels and tRNA decay ratio indicate that tRNA levels in $M E T 22^{+}$ were at or below background, and therefore those values could not be accurately measured.

tRNA decay ratio relative to the corresponding $S U P 4_{o c}$ $A_{29} U$ and $A_{31} U$ variants, but not as much of a reduction as in the corresponding $\mathrm{TY}(\mathrm{GUA})$ variants (Fig. 3D; Supplemental Fig. S8). Presumably, the reduced tRNA decay ratio reflects reduced pre-tRNA decay; however, we note that we could not accurately compare pre-tRNA accumulation or pre-tRNA decay ratios of these variants to the corresponding SUP4 $4_{o c}$ and $\mathrm{tY}(\mathrm{GUA})$ variants, as the $\ln _{11}$ mutation could affect the hybridization of the primer used for these measurements.

\section{Removal of the intron suppresses tRNA decay}

To quantitatively assess the importance of the intron in decay of SUP4 $4_{o c}$ and $\mathrm{tY}(\mathrm{GUA})$ anticodon stem variants subject to MPD, we compared tRNA decay with and without the intron. However, since the intron of $\mathrm{TY}(\mathrm{GUA})$ is known to be required for pseudouridine $(\Psi)$ modification of $U_{35}$ (Urban et al. 2009), we performed these comparisons in a pus7 $\Delta$ strain, in which both the intron-containing and intronless variants would lack $\Psi_{35}$, enabling a more accurate comparison of the effect of intron removal.

Our results show that most of the decay of the $S U P 4_{o c}$ $A_{29} U$ and $A_{31} U$ variant is due to MPD, provoked by the presence of both the intron and the $\mathrm{G}_{34} \mathrm{U}$ mutation of $S U P 4_{o c}$. Thus, the tRNA decay ratio of $S U P 4_{o c} A_{29} \mathrm{U}$ is substantially reduced by intron removal, falling from 7.3 to 2.9 , and the tRNA decay ratio is further reduced (to 1.7) in an intronless $t Y(G U A) A_{29} U$ variant (Fig. 4A,B; Supplemental Fig. S11A). We infer that the increased access of Met22dependent nucleases to $S U P 4_{o c} A_{29} U$ [compared to tY (GUA) $A_{29} U$ ] explains its increased tRNA decay ratio in 
A

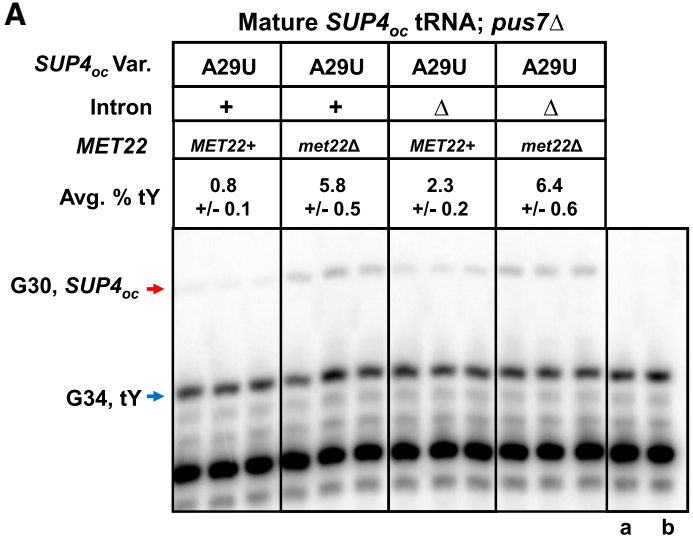

B

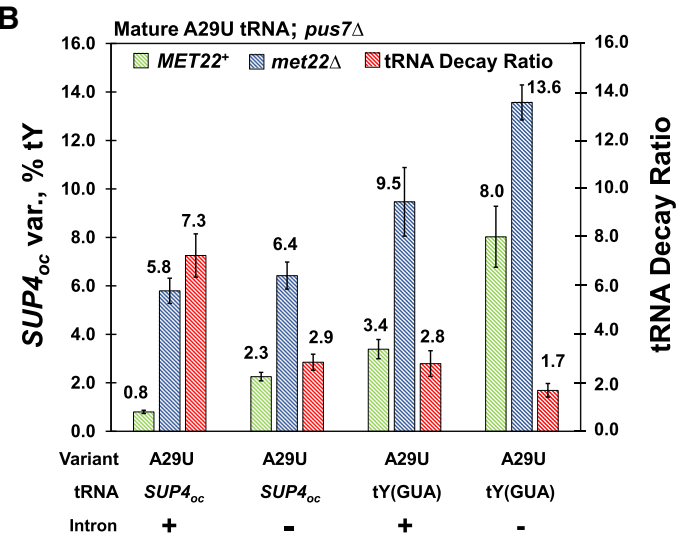

C

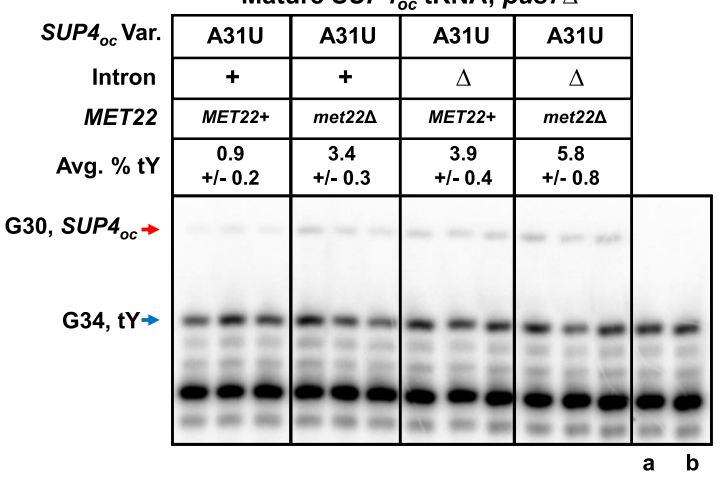

D

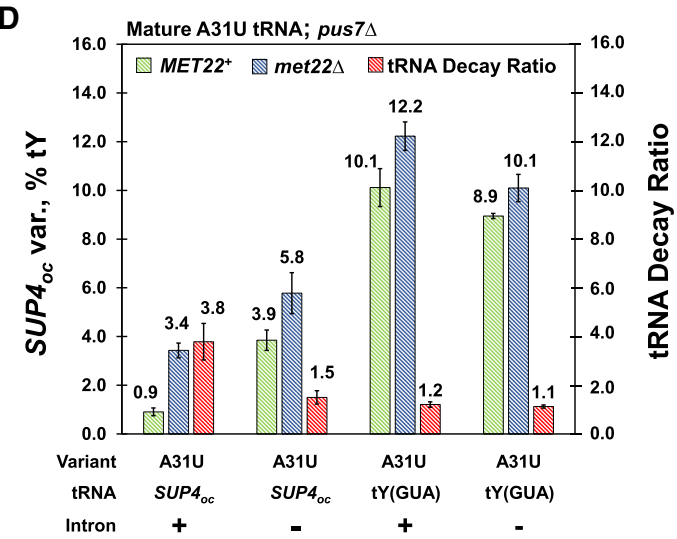

FIGURE 4. tRNA decay of the SUP4 ${ }_{o c} A_{29} U$ and $A_{31} U$ anticodon stem variants is suppressed by removal of the intron and restoration of $G_{34}$. ( $A$ ) Poison primer extension analysis of SUP ${ }_{o c} \mathrm{~A}_{29} \mathrm{U}$ intron-containing and intronless variants. Variants as indicated were analyzed for tRNA levels after growth in pus7 $\Delta$ strains, by poison primer extension analysis using primer P5 (57-37) in the presence of ddCTP. $a$ and $b$, strain with no $S U P 4_{o c}$ variant in MET22 ${ }^{+}$and met22 2 . (B) The decay of $S U P 4_{o c} A_{29} \mathrm{U}$ is suppressed by intron removal and restoration of $\mathrm{G}_{34}$. Bar graph depicting $\% \mathrm{tY}$ levels and tRNA decay ratios for anticodon stem variants with or without an intron in SUP4 $4_{o c}$ and $\mathrm{tY}(\mathrm{GUA})$, as indicated. (C) Poison primer extension analysis of SUP4 ${ }_{o c} A_{31} U$ intron-containing and intronless variants. (D) The decay of $S U P 4_{o c} A_{31} U$ is suppressed by intron removal and restoration of $\mathrm{G}_{34}$.

the intronless variants. These data demonstrate that for the $S U P 4_{o c} A_{29} U$ variant most, but not all, of the tRNA decay is due to MPD, with the remainder presumably due to RTD. Similarly, removal of the intron from SUP $4_{o c} A_{31} U$ reduces the tRNA decay ratio from 3.8 to 1.5 , and restoration of $\mathrm{G}_{34}$ to generate an intronless $\mathrm{t}(\mathrm{GUA}) \mathrm{A}_{31} \mathrm{U}$ variant eliminates virtually all remaining tRNA decay, resulting in a tRNA decay ratio of 1.1 (Fig. 4C,D; Supplemental Fig. S11B).

\section{Anticodon stem mutations cause both RTD and MPD in $\mathrm{tS}$ (CGA)}

The finding of Met22-dependent decay of both mature tRNA (RTD) and pre-tRNA (MPD) associated with SUP4 $4_{o c}$ and $t Y(G \cup A)$ anticodon stem variants led us to speculate that anticodon stem variants of other intron-containing tRNA species would also be subject to some combination of RTD and MPD. We therefore attempted to design tS (CGA) anticodon stem variants that would be subject to
RTD (Fig. 5A), since RTD of tS(CGA) variants is well studied biochemically, and since $\mathrm{tS}(\mathrm{CGA})$ is a single copy essential tRNA gene that is amenable to a genetic test for Met22dependent tRNA decay (Whipple et al. 2011). We integrated a $\mathrm{tS}(\mathrm{CGA})$ anticodon stem variant into a $\mathrm{tS}(\mathrm{CGA}) \Delta$ [URA3 tS(CGA)] strain, so that cell growth dependent on the integrated variant could be tested after FOA selection to remove the URA3 ${ }^{+}$plasmid bearing the WT tS(CGA) gene. We found that strains bearing each of the three tested anticodon stem tS(CGA) variants $\left(\mathrm{A}_{29} \mathrm{U}, \mathrm{C}_{40} \mathrm{U}\right.$, and $\mathrm{C}_{42} \mathrm{U}$ ) behaved like substrates of RTD or MPD, because they exhibited temperature sensitivity that could be suppressed by a met22 $\Delta$ mutation (Fig. 5B), as was observed for the control $\tan 1 \Delta \operatorname{trm} 44 \Delta$ mutant, previously shown to be due to RTD (Chernyakov et al. 2008; Kotelawala et al. 2008).

To assess tRNA decay of these variants, we first introduced a plasmid containing a tS(GCU/CGA) hybrid tRNA, bearing the body of $\mathrm{tS}(\mathrm{GCU})$ and a CGA anticodon, into 
A

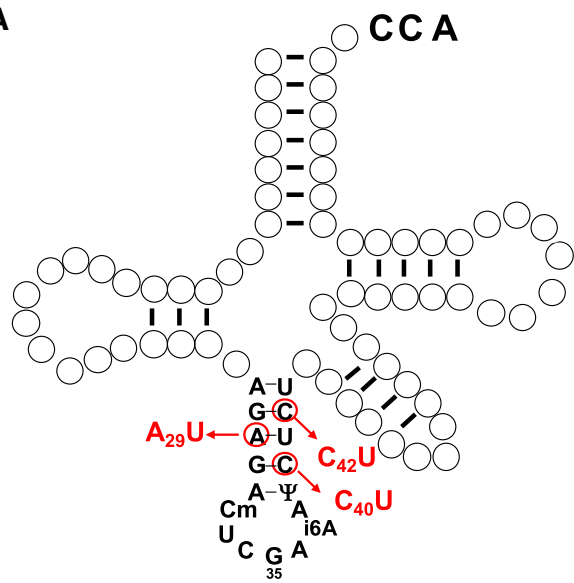

B

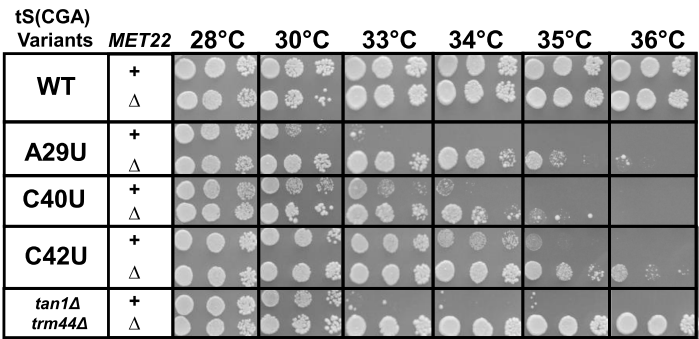

C
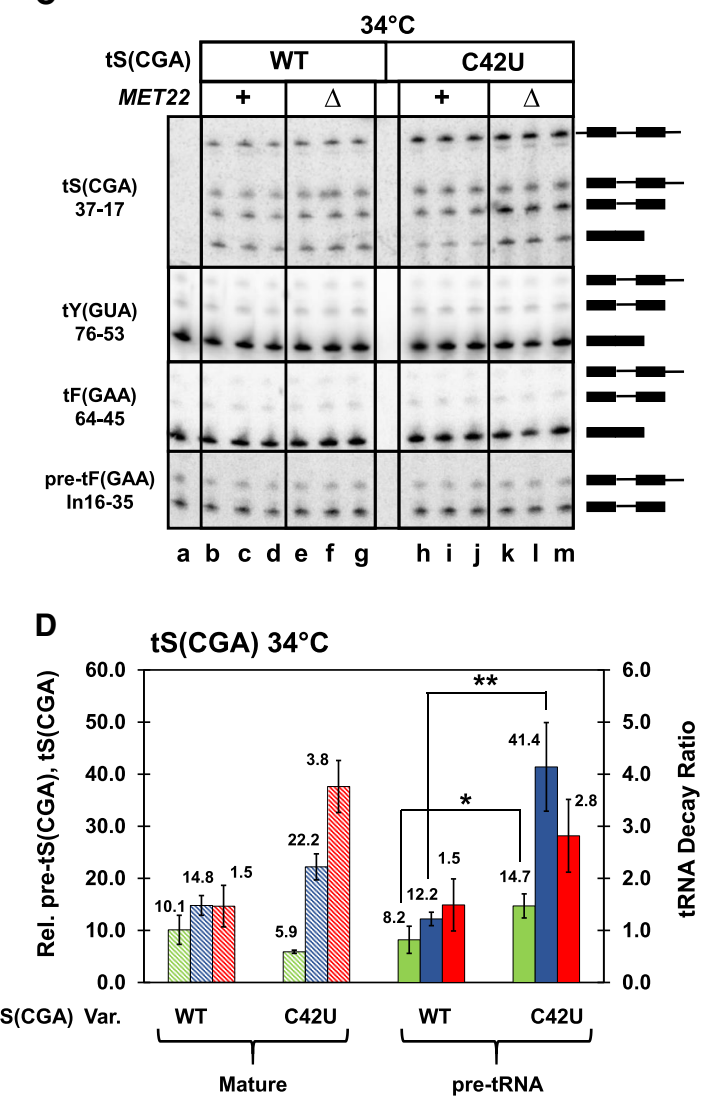

FIGURE 5. Anticodon stem variants of $t S(C G A)$ provoke RTD and MPD. (A) Schematic of mature tS(CGA) and variants analyzed. Variants are indicated in red. (B) Genetic analysis demonstrates that several tS(CGA) anticodon stem variants provoke Met22-dependent decay. MET22 ${ }^{+}$and met22 $\Delta$ strains with a $\mathrm{tS}(\mathrm{CGA}) \Delta$ mutation and a single integrated $\mathrm{tS}(\mathrm{CGA})$ variant as indicated were tested for growth by plating serial dilutions on YPD media and incubating plates at the temperatures indicated. (C) Northern analysis of $\mathrm{tS}(\mathrm{CGA})$ and $\mathrm{tS}(\mathrm{CGA}) \mathrm{C}_{42} \mathrm{U}$ tRNA levels in MET22 ${ }^{+}$and met22 $\Delta$ strains grown at $34^{\circ} \mathrm{C}$. Strains with a $t S(C G A) \Delta$ mutation, an integrated tS(CGA) variant, and a [tS(GCU/CGA) LEU2 CEN] plasmid (to allow for growth at a nonpermissive temperature), were grown at $34^{\circ} \mathrm{C}$, and bulk RNA was resolved by gel electrophoresis and hybridized using labeled probes as indicated at the left. To confirm selective hybridization relative to endogenous $\mathrm{TS}$ (UGA), bulk RNA from a strain with no integrated tS (CGA) variant (lane a) was probed at the same time. (D) The $\mathrm{tS}(\mathrm{CGA}) \mathrm{C}_{42} \mathrm{U}$ variant is subject to RTD and MPD. Pre-tS(CGA) and mature $t S(C G A)$ were quantified relative to hybridization of $\mathrm{tY}(\mathrm{GUA})(\times 100)$ to control for loading, to obtain relative tRNA and pre-tRNA levels, and associated tRNA decay ratios and pre-tRNA decay ratios. The statistical significance of pre-tRNA accumulation was evaluated using a one-tailed

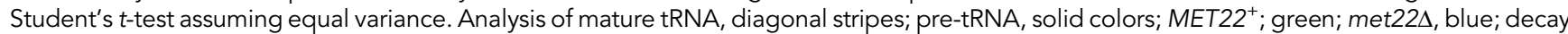
ratios, red.

the $\mathrm{tS}(\mathrm{CGA}) \Delta$ strain with an integrated $\mathrm{tS}(\mathrm{CGA})$ variant, thus allowing growth of strains at nonpermissive temperatures and facile measurement of $\mathrm{tS}(\mathrm{CGA})$ variant levels by northern analysis. At $34^{\circ} \mathrm{C}$, the $\mathrm{tS}(\mathrm{CGA}) \mathrm{C}_{42} \mathrm{U}$ variant had a substantial tRNA decay ratio of 3.8, accompanied by a large accumulation of unspliced end-matured pre-tRNA in the met22 $\Delta$ strain [compared to that of WT tS(CGA)], and a substantial pre-tRNA decay ratio of 2.8 (Fig. $5 \mathrm{C}, \mathrm{D}$ ). At $32^{\circ} \mathrm{C}$, the tS(CGA) $\mathrm{C}_{40} \mathrm{U}$ variant also had a substantial tRNA decay ratio of 3.9 and a distinct pre-tRNA decay ratio of 1.8 (Supplemental Fig. S12), albeit accompanied by a modest accumulation of pre-tRNA in the met22 $\Delta$ background $(P$ value of 0.065 ). It was also clear from our northern analysis of the $\mathrm{tS}(\mathrm{CGA}) \mathrm{C}_{42} \mathrm{U}$ and $\mathrm{C}_{40} \mathrm{U}$ variants that the end-matured intron-containing pre-tRNA species was the target of MPD. In contrast, although the $\mathrm{tS}(\mathrm{CGA}) \mathrm{A}_{29} \mathrm{U}$ variant had a substantial tRNA decay ratio of 2.0, there was no obvious accumulation or decay of pre-tRNA (Supplemental Fig. S13).

\section{DISCUSSION}

The results described here show that decay of anticodon stem tRNA variants occurs in large part through a previously undescribed Met22-dependent decay pathway that targets pre-tRNAs that accumulate due to altered structure of the anticodon stem-loop and intron. Pre-tRNA decay by the MPD pathway can contribute substantially to the overall decay of tRNA variants as mutations that suppress MPD or remove the intron result in a substantial reduction of the 
tRNA decay ratio. Furthermore, MPD is a general phenomenon, as it can occur in both $\mathrm{tY}(\mathrm{GUA})$ and $\mathrm{tS}(\mathrm{CGA})$ variants bearing native anticodons and thus participating in normal translation. In all previously described cases, Met22 has only been shown to regulate mature tRNA decay by the RTD pathway (Alexandrov et al. 2006; Chernyakov et al. 2008; Dewe et al. 2012), and the decay of pre-tRNA has only been attributed to $3^{\prime}-5^{\prime}$ exonucleolytic decay by the nuclear surveillance pathway (Kadaba et al. 2004, 2006; Gudipati et al. 2012).

The accumulation of pre-tRNA that drives MPD is likely directly related to the structure of the pre-tRNA anticodon stem-loop and intron, which is important for splicing. Pairing between intron residues and residues of the anticodon and neighboring nucleotides is highly conserved in archaeal and yeast intron-containing pre-tRNAs, comprising the central helix of the bulge-helix-bulge motif important for splicing (Ogden et al. 1984; Swerdlow and Guthrie 1984; Lee and Knapp 1985; Kjems et al. 1989; Thompson and Daniels 1990; Marck and Grosjean 2003; Xue et al. 2006). The importance of the central helix is underscored by our results that disruption of this helix by a $\mathrm{G}_{34} \mathrm{U}$ mutation tended to increase MPD, whereas restoration of the helix tended to reduce MPD. Remarkably, we found that a complete disruption of this interaction in the SUP4 CAC variant is sufficient to provoke MPD without any other accessory mutations. The importance of the $3^{\prime}$ bulge structure is underscored by prominent pre-tRNA decay in variants predicted to have an intact central helix, but with mutations affecting the bulge, including the $t Y(G \cup A) G_{30} A, t S(C G A) C_{40} U$, and $t S(C G A)$ $\mathrm{C}_{42} \mathrm{U}$ variants.

The Met22-dependent decay of end-matured unspliced pre-tRNA documented here might extend to other organisms. Introns are found in at least some tRNA genes throughout eukaryotes, including humans, and the metazoan tRNA splicing pathway uses a similar endonuclease, likely recognizing pre-tRNA in a similar fashion (Fruscoloni et al. 2001). Presumably, the integrity of pre-tRNA structure is under similar surveillance in other eukaryotes.

Our data shows that the target of pre-tRNA decay by the MPD pathway is the end-matured unspliced species, for both $\mathrm{tY}(\mathrm{GUA})$ and $\mathrm{tS}(\mathrm{CGA})$ variants. This pre-tRNA species is the last end processing intermediate before nuclear export of the pre-tRNA for splicing on the surface of the mitochondrion (Yoshihisa et al. 2003, 2007; Wan and Hopper 2018). Thus, MPD could occur in the nucleus just after end processing, or in the cytoplasm after export. Since perturbed exon-intron structure is a strong determinant of MPD and is linked to impaired splicing, we anticipate that MPD is more likely to occur in the cytoplasm, where splicing occurs. Although we do not yet unequivocally know the nucleases responsible for MPD, the Met22-dependence of pre-tRNA decay suggests strongly that MPD is due to a $5^{\prime}-3^{\prime}$ exonuclease, as this class of nucleas- es is known to be inhibited in a met22 $\Delta$ strain (Dichtl et al. 1997; Yun et al. 2018). Indeed Xrn1 and Rat1 are the known $5^{\prime}-3^{\prime}$ exonucleases of RTD, which are inhibited in met22 $\Delta$ strains (Chernyakov et al. 2008; Whipple et al. 2011). However, we note that other nucleases could also be involved as there is at least one report of a $3^{\prime}-5^{\prime}$ exonuclease that is inhibited by pAp (Mechold et al. 2006), and in principle an endonuclease could also be inhibited by pAp.

We envision two mechanisms by which MPD might occur. First, the accumulation of pre-tRNAs due to inefficient endonucleolytic cleavage during splicing may provide the substrate for degradation by $5^{\prime}-3^{\prime}$ exonucleases, due to the increased availability of the pre-tRNAs. We note that a pre-tRNA that accumulates before the onset of splicing might be uniquely vulnerable to attack by $5^{\prime}-3^{\prime}$ exonucleases, as decay of the pre-tRNA, unlike decay of mature tRNA during RTD, would not be blocked by binding to EF-1A or the aminoacyl tRNA synthetases, both of which prevent RTD (Dewe et al. 2012; Turowski et al. 2012), and would also not be expected to be protected by the ribosome. Second, MPD may be mediated through a more complex decay pathway involving the SEN complex itself. In this model, pre-tRNA with a compromised structure might be inefficiently spliced by the SEN complex at either the $5^{\prime}$ or $3^{\prime}$ splice junction, generating tRNA fragments with exposed $5^{\prime}$ and $3^{\prime}$ ends at the acceptor stem. At this step, the tRNA fragments would be in competition among three different fates: completion of endonucleolytic cleavage by the SEN complex; healing and religation by the tRNA ligase (Trl1); or decay by exonucleases. This type of model was recently proposed as a mechanism regulating decay of HAC1 mRNA, encoding a major regulator of the unfolded protein response; this mRNA is spliced by a similar mechanism to tRNA, using Ire1 endonuclease and tRNA ligase (Sidrauski et al. 1996; Sidrauski and Walter 1997), and ligation of its cleavage products is in competition with decay mediated by Xrn1 (Cherry et al. 2019; Peschek and Walter 2019). Future experiments should cast light on the mechanism by which the MPD pathway monitors pre-tRNA quality and mediates decay.

The identification of MPD also has implications for the tRNAs of higher eukaryotes, which are often made up of several isodecoders, tRNAs with identical anticodons, but variations in the remaining sequence and the intron (Goodenbour and Pan 2006). Of particular note to the work described here, the four human tRNA isodecoder families with introns have substantial intron variations in both length and sequence content (Chan and Lowe 2016). It has been previously reported that $t R(U C U)$ isodecoders are subject to tissue specific regulation of expression (Ishimura et al. 2014), and based on the work described here, intronic variations could in principle participate in regulating expression through an MPD-like pathway. 
TABLE 1. Strains used in this study

\begin{tabular}{|c|c|c|}
\hline Strain name & Genotype & Origin \\
\hline BCY 123 & MATa pep4 $\Delta::$ HIS3 prb4::LEU2 bar14::HISG lys24::GAL1/10-GALA4 can1 ade2 ura3 leu2-3, 112 & (Macbeth et al. 2005 \\
\hline BY 4741 & MATa his3 11 leu2 $\Delta 0$ met15 $\Delta 0$ ura3 $3 \Delta 0$ & Open biosystems \\
\hline ISC 566 & 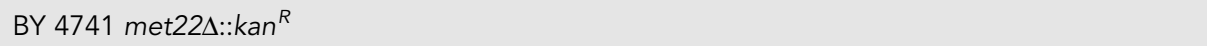 & This study \\
\hline JMW 223 & BY $4741 \mathrm{tS}(\mathrm{CGA}) \Delta:: b l e^{R}[\mathrm{tS}(\mathrm{CGA})$ URA3 CEN] & (Whipple et al. 2011) \\
\hline JMW 451 & 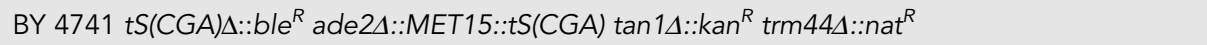 & (Whipple et al. 2011) \\
\hline JMW 549 & 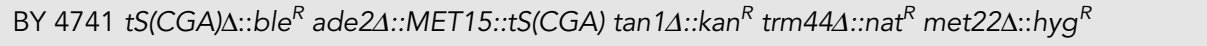 & (Whipple et al. 2011) \\
\hline QB 1112AD & $\mathrm{BCY} 123\left[2 \mu \mathrm{P}_{\mathrm{GAL}}-\mathrm{XRN1-PT}\right]$ & (Quartley et al. 2009) \\
\hline QB 1222AD & $\mathrm{BCY} 123\left[2 \mu \mathrm{P}_{\mathrm{GAL}}-\mathrm{RAT1}-\mathrm{PT} / \mathrm{His}_{10}-\mathrm{RAI1}\right]$ & (Quartley et al. 2009) \\
\hline YK 380-1 & BY4741 can 14::RNA-ID GFP oc MET15 & (Guy et al. 2014) \\
\hline YK 391-1 & BY4741 can $1 \Delta:: R N A-I D$ GFP oc MET15 met224::kan ${ }^{R}$ & (Guy et al. 2014) \\
\hline YAH592-1 & YK380-1 pus74:: ble ${ }^{R}$ & This study \\
\hline YAH593-1 & YK391-1 pus74::ble ${ }^{R}$ & This study \\
\hline
\end{tabular}

\section{MATERIALS AND METHODS}

\section{Yeast strains}

The yeast strains used are shown in Table 1. Deletions were introduced by standard PCR amplification of the appropriate strain from the YKO collection (Giaever et al. 2002) (or of a derivative strain with a different drug marker), followed by a linear transformation, and PCR of transformants to confirm the deletion.

\section{Construction and integration of variants of $\mathrm{SUP}_{o c}$ and $\mathrm{tS}(\mathrm{CGA})$}

SUP $4_{o c}$ variants were constructed by annealing of overlapping oligomers (IDT) followed by ligation into the Bgl II Xho I site of the tRNA gene cassette of plasmid AB230-1, as previously described (Guy et al. 2014). tS(CGA) variants were constructed in a similar manner. tRNA variants were integrated at the ADE2 site of strains by a linear transformation of a Stu I fragment containing the tRNA cassette, the adjacent HIS3 marker, and flanking ADE2 sequences, deleting part of ADE2 (Whipple et al. 2011). Three biological isolates of each strain were isolated and used for all of the experiments reported, unless otherwise noted.

\section{Growth of cells for isolation of bulk RNA}

Three independent isolates of strains with integrated tRNA variants were grown overnight at $28^{\circ} \mathrm{C}$ in $5 \mathrm{~mL}$ YPD media ( $1 \%$ yeast extract, $2 \%$ peptone, $2 \%$ dextrose, supplemented with $80 \mathrm{mg} / \mathrm{L}$ adenine hemisulfate), inoculated into $5 \mathrm{~mL}$ fresh media at $\mathrm{OD}_{600} \sim 0.1$, and grown to an $\mathrm{OD} \sim 1$, and then 2-OD samples were harvested with a microcentrifuge, washed with $1 \mathrm{~mL}$ water, frozen on dry ice, and stored at $-80^{\circ} \mathrm{C}$. Then bulk RNA was extracted using hot phenol as described previously (Jackman et al. 2003), followed by addition of $20 \mu \mathrm{g}$ glycogen, phenol-chloroform-isoamyl alcohol (PCA) extraction, two ethanol precipitations, and resuspension in $\mathrm{dd}_{2} \mathrm{O}$.

\section{Purification of Xrn1 and the Rat1/Rai1 complex}

Xrn1 was purified from yeast strain QB1122AD after galactoseinduced expression of a $\mathrm{P}_{\mathrm{GAL} 1}-\mathrm{XRN} 1$ construct in which $\mathrm{XRN1}$ was fused at its $3^{\prime}$ terminus to the PT tag, bearing a protease $3 \mathrm{C}$ site- HA epitope- His6- ZZ domain of protein A, as described previously (Whipple et al. 2011). Rat1/Rai1 was purified analogously from strain QB1222AD bearing a dual $P_{G A L 1,10}$ expression plasmid expressing RAT1-PT and His10-RAl1 (Quartley et al. 2009).

TABLE 2. Primers used in poison primer extension

\begin{tabular}{llcl}
\hline Name & Target RNA & Probe $\left(5^{\prime}-3^{\prime}\right)$ & Sequence \\
\hline P5 & tY(GUA) & $57-37$ & CGAACGCCCGATCTCAAGATT \\
P7 & tY(GUA) & $62-43$ & CGAGTCGAACGCCCGATCTC \\
P9 & tY(GUA) & $57-33$ & CGAACGCCCGATCTCAAGATTTACA \\
MP 539 & tY(GUA) & $55-31$ & AACGCCCGATCTCAAGATTTACAGT \\
MP 497 & pre-tY(GUA) & $51-\ln 1$ & CCCGATCTCAAGATTTCGTAGTGATAAA \\
MP 538 & pre-tY(GUA) & c9-[In]-34 GATCTCAAGATTTCGTAGTGATAAATTAC \\
MP 540 & pre-tY(GUA) & $46-[\ln ]-31$ & TCTCAAGATTTCGTAGTGATAAATTACTGT \\
\hline
\end{tabular}


TABLE 3. Oligomers used for northern analysis

\begin{tabular}{|c|c|c|c|}
\hline Name & Target RNA & Probe $\left(5^{\prime}-3^{\prime}\right)$ & Sequence \\
\hline TDZ 231 & SUP4 ${ }_{o c} \mathrm{~A} 29 \mathrm{U}$ & $48-27$ & GATCTCAAGATTTAAAGTCATG \\
\hline TDZ 271 & SUP4 ${ }_{o c}$ G30A & $48-27$ & GATCTCAAGATTTAAAGTTTTG \\
\hline TDZ 249 & SUP $4_{o c} \mathrm{~A} 31 \mathrm{U}$ & $48-27$ & GATCTCAAGATTTAAAGACTTG \\
\hline tRNAPheLoop & $\mathrm{tF}(\mathrm{GAA})$ & $64-45$ & TGTGGATCGAACACAGGACC \\
\hline MP 586 & $\mathrm{tS}(\mathrm{CGA})$ & $37-17$ & TTCGAGTCTCTCGCCTTAACCA \\
\hline MP 197 & $\mathrm{tY}(\mathrm{GUA})$ & $76-53$ & TGGTCTCCCGGGGGCGAGTCGAACG \\
\hline Phe GAA intron & pre-tF(GAA) & $\ln 16-35$ & TTGACCGAAGTTTTTTCTT \\
\hline MP 564 & pre-tY(GUA) & $43-\ln 1$ & CAAGATTTCGTAGTGATAAA \\
\hline MP 567 & pre-SUP4 ${ }_{o c} \mathrm{~A} 29 \mathrm{U}$ & $\ln 14-27$ & TTCGTAGTGATAAATTAAAGTCATG \\
\hline TDZ 238 & pre-SUP4 $4_{o c} \mathrm{G} 30 \mathrm{~A}$ & $\ln 14-27$ & TTCGTAGTGATAAATTAAAGTTTTG \\
\hline TDZ 239 & pre-SUP4 $4_{o c} \mathrm{~A} 31 \mathrm{U}$ & $\ln 14-27$ & TTCGTAGTGATAAATTAAAGACTTG \\
\hline $5 S$ & $5 S$ & $20-1$ & TGGTAGATATGGCCGCAACC \\
\hline
\end{tabular}

\section{Purification of tRNAs}

SUP4 $4_{o c}$ variants were purified together with tRNA ${ }^{\text {Tyr }}$ using $1.0 \mathrm{mg}$ bulk RNA from the corresponding met22 $\Delta$ strain and the biotinylated oligomer MP 129 (nt 76-53), as previously described (Gehrke and Kuo 1989; Whipple et al. 2011).

\section{In vitro digestion with exonucleases}

Purified tRNAs were analyzed for exonuclease sensitivity essentially as previously described (Whipple et al. 2011). A purified mixture of $\mathrm{tY}(\mathrm{GUA})$ and $S U P 4_{o c}(7.5 \mathrm{ng})$ was melted at $95^{\circ} \mathrm{C}$ for $10 \mathrm{~min}$ in buffer containing $25 \mathrm{mM}$ Tris $\mathrm{pH} 8.0$ and $150 \mathrm{mM} \mathrm{NaCl}$, immediately placed on ice, refolded at $37^{\circ} \mathrm{C}$ for $20 \mathrm{~min}$ in buffer containing $13.9 \mathrm{mM}$ Tris $\mathrm{pH} 8.0,83.3 \mathrm{mM} \mathrm{NaCl}, 2.2 \mathrm{mM} \mathrm{MgCl}$, $0.55 \mathrm{mM}$ DTT, $0.11 \mathrm{mg} / \mathrm{mL}$ BSA, and then incubated as indicated with purified Xrn1 or Rat1/Rai1 in buffer containing $4.5 \mathrm{mM}$ Tris $\mathrm{pH}$ 8.0, $90 \mathrm{mM} \mathrm{NaCl}, 2.1 \mathrm{mM} \mathrm{MgCl}, 0.6 \mathrm{mM} \mathrm{DTT}, 0.1 \mathrm{mg} / \mathrm{mL}$ BSA, 5\% glycerol. Reactions were stopped on dry ice, extracted with PCA, ethanol precipitated with $20 \mu \mathrm{g}$ of glycogen, and then resuspended in $\mathrm{dd}_{2} \mathrm{O}$.

\section{Poison primer extension analysis of SUP4 ${ }_{o c}$ variants}

To analyze relative amounts of SUP4 $4_{o c}$ and tRNA ${ }^{\text {Tyr }}$ in bulk RNA or purified mixtures, we used a poison primer extension assay with an appropriate primer (Table 2) and ddCTP or ddTTP, essentially as previously described (Guy et al. 2014). Briefly, 0.5 pmol of $5^{\prime}$ radiolabeled primer and $\sim 1.0 \mu \mathrm{g}$ of bulk RNA was denatured by heating at $95^{\circ} \mathrm{C}$ and then annealed in water, followed by primer extension with $2 \mathrm{U}$ AMV reverse transcriptase (Promega) in supplied buffer containing $1 \mathrm{mM}$ ddNTP, and $1 \mathrm{mM}$ remaining dNTPs, incubation for $1 \mathrm{~h}$ at $50^{\circ} \mathrm{C}$, and transfer to $-20^{\circ} \mathrm{C}$. Aliquots of reactions were diluted twofold in formamide dye, heated at $95^{\circ} \mathrm{C}$ for $3 \mathrm{~min}$, and resolved on a $15 \%$ polyacrylamide gel (29:1) containing $7 \mathrm{M}$ urea in $1 \times$ TBE. The gel was dried on a Model 583 Biorad gel dryer at $78^{\circ} \mathrm{C}$ for $40 \mathrm{~min}$, exposed and an- alyzed using an Amersham Typhoon phosphoimager and Image Quant v5.2.

The relative amount of SUP4 $4_{o c}$ variant in each sample is expressed as \% tY(GUA) (\% tY), calculated as the quotient of the signal for the SUP4 ${ }_{o c}$ variant (typically the $G_{30}$ stop) divided by the endogenous $\mathrm{t} Y(\mathrm{GUA})$ signal (typically the $\mathrm{G}_{34}$ stop), each first corrected for background. The \% tY was averaged over three biologically independent strains grown and analyzed in parallel, and the error calculated as a standard deviation. The RTD ratios were calculated as the quotient of the average $\% \mathrm{tY}$ value in a met22 $\Delta$ strain divided by the corresponding average $\%$ tY value in a $\mathrm{MET}_{22}{ }^{+}$strain (analyzed in the same gel from primer extensions done at the same time), with the error propagated appropriately for a division operation.

We note that despite some variability in \% tY from experiment

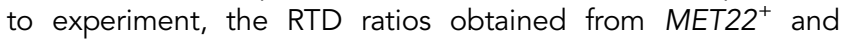
met22 $\Delta$ strains grown in triplicate and analyzed at the same time are largely consistent between experiments. The variability in \% tY likely arises from variations in the hybridization efficiencies of the primer extension probe to SUP4 ${ }_{o c}$ variants in different sets of assays. This results in variable $\% \mathrm{tY}$ measurements for the same bulk RNA preparations assayed at different times, but the same \% tY from biological triplicates assayed at the same time.

\section{Northern analysis of SUP4 ${ }_{o c}$ variants}

For northern analysis, independently made strains were grown in parallel, bulk RNA was isolated, and $1 \mu \mathrm{g}$ of bulk RNA was mixed with an equal volume formamide dye, heated at $60^{\circ} \mathrm{C}$ for $5 \mathrm{~min}$, and resolved on a $10 \%$ polyacrylamide (19:1), $7 \mathrm{M}$ urea $1 \times$ TBE gel, which was transferred onto an Amersham Hybond- $\mathrm{N}^{+}$membrane (GE Healthcare), crosslinked on a UV Stratalinker 2400, and hybridized to probes ( 12 pmol 5' ${ }^{32}$ P-labeled DNA oligomer) as indicated. Oligomers are described in Table 3.

\section{SUPPLEMENTAL MATERIAL}

Supplemental material is available for this article. 


\section{ACKNOWLEDGMENTS}

We thank Elizabeth Grayhack for valuable discussions during the course of this work and for comments on the manuscript. This research was supported by National Institutes of Health, National Institute of General Medical Sciences (NIH/NIGMS) grant GM052347 to E.M.P. M.J.P. was partially supported by NIH/ NIGMS Training Grant GM068411 in Cellular, Biochemical, and Molecular Sciences.

Received August 29, 2019; accepted October 11, 2019.

\section{REFERENCES}

Agris PF, Vendeix FA, Graham WD. 2007. tRNA's wobble decoding of the genome: 40 years of modification. J Mol Bio/ 366: 1-13. doi:10 $.1016 /$ j.jmb.2006.11.046

Alexandrov A, Chernyakov I, Gu W, Hiley SL, Hughes TR, Grayhack EJ, Phizicky EM. 2006. Rapid tRNA decay can result from lack of nonessential modifications. Mol Cell 21: 87-96. doi:10.1016/j.molcel .2005 .10 .036

Bierhals T, Korenke GC, Uyanik G, Kutsche K. 2013. Pontocerebellar hypoplasia type 2 and TSEN2: review of the literature and two novel mutations. Eur J Med Genet 56: 325-330. doi:10.1016/j.ejmg .2013.03.009

Boczonadi V, Jennings MJ, Horvath R. 2018. The role of tRNA synthetases in neurological and neuromuscular disorders. FEBS Lett 592: 703-717. doi:10.1002/1873-3468.12962

Breuss MW, Sultan T, James KN, Rosti RO, Scott E, Musaev D, Furia B, Reis A, Sticht H, Al-Owain M, et al. 2016. Autosomal-recessive mutations in the tRNA splicing endonuclease subunit TSEN15 cause pontocerebellar hypoplasia and progressive microcephaly. Am J Hum Genet 99: 228-235. doi:10.1016/j.ajhg.2016.05.023

Budde BS, Namavar Y, Barth PG, Poll-The BT, Nürnberg G, Becker C, van Ruissen F, Weterman MA, Fluiter K, te Beek ET, et al. 2008. tRNA splicing endonuclease mutations cause pontocerebellar hypoplasia. Nat Genet 40: 1113-1118. doi:10.1038/ng.204

Chan PP, Lowe TM. 2016. GtRNAdb 2.0: an expanded database of transfer RNA genes identified in complete and draft genomes. Nucleic Acids Res 44: D184-D189. doi:10.1093/nar/gkv1309

Chernyakov I, Whipple JM, Kotelawala L, Grayhack EJ, Phizicky EM. 2008. Degradation of several hypomodified mature tRNA species in Saccharomyces cerevisiae is mediated by Met22 and the $5^{\prime}-3^{\prime}$ exonucleases Rat1 and Xrn1. Genes Dev 22: 1369-1380. doi:10 $.1101 /$ gad.1654308

Cherry PD, Peach SE, Hesselberth JR. 2019. Multiple decay events target HAC1 mRNA during splicing to regulate the unfolded protein response. Elife 8: e42262. doi:10.7554/eLife.42262

de Brouwer APM, Abou Jamra R, Körtel N, Soyris C, Polla DL, Safra M, Zisso A, Powell CA, Rebelo-Guiomar P, Dinges N, et al. 2018. Variants in PUS7 cause intellectual disability with speech delay, microcephaly, short stature, and aggressive behavior. Am J Hum Genet 103: 1045-1052. doi:10.1016/j.ajhg.2018.10.026

Demeshkina N, Jenner L, Westhof E, Yusupov M, Yusupova G. 2012. A new understanding of the decoding principle on the ribosome. Nature 484: 256-259. doi:10.1038/nature10913

Dewe JM, Whipple JM, Chernyakov I, Jaramillo LN, Phizicky EM. 2012. The yeast rapid tRNA decay pathway competes with elongation factor $1 \mathrm{~A}$ for substrate tRNAs and acts on tRNAs lacking one or more of several modifications. RNA 18: 1886-1896. doi:10.1261/ rna.033654.112

Dichtl B, Stevens A, Tollervey D. 1997. Lithium toxicity in yeast is due to the inhibition of RNA processing enzymes. EMBO J 16: 71847195. doi:10.1093/emboj/16.23.7184
Etcheverry T, Colby D, Guthrie C. 1979. A precursor to a minor species of yeast tRNA ${ }^{\text {Ser }}$ contains an intervening sequence. Cell 18: 11-26. doi:10.1016/0092-8674(79)90349-0

Fechter P, Rudinger-Thirion J, Théobald-Dietrich A, Giegé R. 2000. Identity of tRNA for yeast tyrosyl-tRNA synthetase: tyrosylation is more sensitive to identity nucleotides than to structural features. Biochemistry 39: 1725-1733. doi:10.1021/bi992276t

Fruscoloni P, Baldi MI, Tocchini-Valentini GP. 2001. Cleavage of nontRNA substrates by eukaryal tRNA splicing endonucleases. EMBO Rep 2: 217-221. doi:10.1093/embo-reports/kve040

Gehrke CW, Kuo KC. 1989. Ribonucleoside analysis by reversedphase high-performance liquid chromatography. J Chromatogr 471: 3-36. doi:10.1016/S0021-9673(00)94152-9

Giaever G, Chu AM, Ni L, Connelly C, Riles L, Véronneau S, Dow S, Lucau-Danila A, Anderson K, André B, et al. 2002. Functional profiling of the Saccharomyces cerevisiae genome. Nature 418: 387391. doi:10.1038/nature00935

Giege R, Sissler M, Florentz C. 1998. Universal rules and idiosyncratic features in tRNA identity. Nucleic Acids Res 26: 5017-5035. doi:10 $.1093 / \mathrm{nar} / 26.22 .5017$

Giege R, Jühling F, Pütz J, Stadler P, Sauter C, Florentz C. 2012. Structure of transfer RNAs: similarity and variability. WIRES RNA 3: 37-61. doi:10.1002/wrna.103

Gillis D, Krishnamohan A, Yaacov B, Shaag A, Jackman JE, Elpeleg O. 2014. TRMT10A dysfunction is associated with abnormalities in glucose homeostasis, short stature and microcephaly. J Med Genet 51: 581-586. doi:10.1136/jmedgenet-2014-102282

Goodenbour JM, Pan T. 2006. Diversity of tRNA genes in eukaryotes. Nucleic Acids Res 34: 6137-6146. doi:10.1093/nar/gkl725

Gudipati RK, Xu Z, Lebreton A, Séraphin B, Steinmetz LM, Jacquier A, Libri D. 2012. Extensive degradation of RNA precursors by the exosome in wild-type cells. Mol Cell 48: 409-421. doi:10.1016/j .molcel.2012.08.018

Guy MP, Young DL, Payea MJ, Zhang X, Kon Y, Dean KM, Grayhack EJ, Mathews DH, Fields S, Phizicky EM. 2014. Identification of the determinants of tRNA function and susceptibility to rapid tRNA decay by high-throughput in vivo analysis. Genes Dev 28: 1721-1732. doi:10.1101/gad.245936.114

Guy MP, Shaw M, Weiner CL, Hobson L, Stark Z, Rose K, Kalscheuer VM, Gecz J, Phizicky EM. 2015. Defects in tRNA anticodon loop 2'-O-methylation are implicated in nonsyndromic $X$ linked intellectual disability due to mutations in FTSJ1. Hum Mutat 36: 1176-1187. doi:10.1002/humu.22897

Hopper AK. 2013. Transfer RNA post-transcriptional processing, turnover, and subcellular dynamics in the yeast Saccharomyces cerevisiae. Genetics 194: 43-67. doi:10.1534/genetics.112.147470

Ishimura R, Nagy G, Dotu I, Zhou H, Yang XL, Schimmel P, Senju S, Nishimura Y, Chuang JH, Ackerman SL. 2014. RNA function. Ribosome stalling induced by mutation of a CNS-specific tRNA causes neurodegeneration. Science 345: 455-459. doi:10.1126/ science.1249749

Jackman JE, Montange RK, Malik HS, Phizicky EM. 2003. Identification of the yeast gene encoding the tRNA m1G methyltransferase responsible for modification at position 9. RNA 9: 574-585. doi:10.1261/rna.5070303

Kadaba S, Krueger A, Trice T, Krecic AM, Hinnebusch AG, Anderson J. 2004. Nuclear surveillance and degradation of hypomodified initiator tRNA ${ }^{\text {Met }}$ in S. cerevisiae. Genes Dev 18: 12271240. doi:10.1101/gad.1183804

Kadaba S, Wang X, Anderson JT. 2006. Nuclear RNA surveillance in Saccharomyces cerevisiae: Trf4p-dependent polyadenylation of nascent hypomethylated tRNA and an aberrant form of 5S rRNA. RNA 12: 508-521. doi:10.1261/rna.2305406

Karlsborn T, Tükenmez H, Chen C, Byström AS. 2014. Familial dysautonomia (FD) patients have reduced levels of the modified wobble 
nucleoside $\mathrm{mcm}^{5} \mathrm{~s}^{2} \mathrm{U}$ in tRNA. Biochem Biophys Res Comm 454: 441-445. doi:10.1016/j.bbrc.2014.10.116

Kermgard E, Yang Z, Michel AM, Simari R, Wong J, Ibba M, Lazazzera BA. 2017. Quality control by isoleucyl-tRNA synthetase of Bacillus subtilis is required for efficient sporulation. Sci Rep 7: 41763. doi:10.1038/srep41763

Kim SH, Suddath FL, Quigley GJ, McPherson A, Sussman JL, Wang AH, Seeman NC, Rich A. 1974. Three-dimensional tertiary structure of yeast phenylalanine transfer RNA. Science 185: 435440. doi:10.1126/science.185.4149.435

Kjems J, Jensen J, Olesen T, Garrett RA. 1989. Comparison of transfer RNA and ribosomal RNA intron splicing in the extreme thermophile and archaebacterium Desulfurococcus mobilis. Can $J$ Microbiol 35: 210-214. doi:10.1139/m89-033

Kotelawala L, Grayhack EJ, Phizicky EM. 2008. Identification of yeast tRNA Um 44 2'-O-methyltransferase (Trm44) and demonstration of a Trm44 role in sustaining levels of specific tRNA ${ }^{\text {Ser }}$ species. RNA 14: 158-169. doi:10.1261/rna.811008

Kramer EB, Hopper AK. 2013. Retrograde transfer RNA nuclear import provides a new level of tRNA quality control in Saccharomyces cerevisiae. Proc Natl Acad Sci 110: 21042-21047. doi:10.1073/pnas .1316579110

LaCava J, Houseley J, Saveanu C, Petfalski E, Thompson E, Jacquier A, Tollervey D. 2005. RNA degradation by the exosome is promoted by a nuclear polyadenylation complex. Cell 121: 713724. doi:10.1016/j.cell.2005.04.029

Ladner JE, Jack A, Robertus JD, Brown RS, Rhodes D, Clark BF, Klug A. 1975. Structure of yeast phenylalanine transfer RNA at 2.5 A resolution. Proc Natl Acad Sci 72: 4414-4418. doi:10 .1073/pnas.72.11.4414

Lee MC, Knapp G. 1985. Transfer RNA splicing in Saccharomyces cerevisiae. Secondary and tertiary structures of the substrates. J Biol Chem 260: 3108-3115.

Lee JW, Beebe K, Nangle LA, Jang J, Longo-Guess CM, Cook SA, Davisson MT, Sundberg JP, Schimmel P, Ackerman SL. 2006. Editing-defective tRNA synthetase causes protein misfolding and neurodegeneration. Nature 443: 50-55. doi:10.1038/ nature05096

Loveland AB, Demo G, Grigorieff N, Korostelev AA. 2017. Ensemble cryo-EM elucidates the mechanism of translation fidelity. Nature 546: 113-117. doi:10.1038/nature22397

Lund E, Dahlberg JE. 1998. Proofreading and aminoacylation of tRNAs before export from the nucleus. Science 282: 2082-2085. doi:10.1126/science.282.5396.2082

Macbeth MR, Schubert HL, Vandemark AP, Lingam AT, Hill CP, Bass BL. 2005. Inositol hexakisphosphate is bound in the ADAR2 core and required for RNA editing. Science 309: 1534-1539. doi:10.1126/science.1113150

Marck C, Grosjean H. 2002. tRNomics: analysis of tRNA genes from 50 genomes of Eukarya, Archaea, and Bacteria reveals anticodonsparing strategies and domain-specific features. RNA 8: 11891232. doi: $10.1017 / \mathrm{S} 1355838202022021$

Marck C, Grosjean H. 2003. Identification of BHB splicing motifs in intron-containing tRNAs from 18 archaea: evolutionary implications. RNA 9: 1516-1531. doi:10.1261/rna.5132503

Mechold U, Ogryzko V, Ngo S, Danchin A. 2006. Oligoribonuclease is a common downstream target of lithium-induced pAp accumulation in Escherichia coli and human cells. Nucleic Acids Res 34: 2364-2373. doi:10.1093/nar/gkl247

Murguía JR, Bellés JM, Serrano R. 1996. The yeast HAL2 nucleotidase is an in vivo target of salt toxicity. J Biol Chem 271: 29029-29033. doi:10.1074/jbc.271.46.29029

Murphy F, Ramakrishnan V, Malkiewicz A, Agris PF. 2004. The role of modifications in codon discrimination by tRNA ${ }^{\text {Lys }}$ UuU. Nat Struct Mol Biol 11: 1186-1191. doi:10.1038/nsmb861
Murthi A, Shaheen HH, Huang HY, Preston MA, Lai TP, Phizicky EM, Hopper AK. 2010. Regulation of tRNA bidirectional nuclear-cytoplasmic trafficking in Saccharomyces cerevisiae. Mol Biol Cell 21: 639-649. doi:10.1091/mbc.e09-07-0551

Nishikura K, De Robertis EM. 1981. RNA processing in microinjected Xenopus oocytes. Sequential addition of base modifications in the spliced transfer RNA. J Mol Biol 145: 405-420. doi:10.1016/00222836(81)90212-6

Nishikura K, Kurjan J, Hall BD, De Robertis EM. 1982. Genetic analysis of the processing of a spliced tRNA. EMBO J 1: 263-268. doi:10 .1002/j.1460-2075.1982.tb01157.x

Ogden RC, Lee MC, Knapp G. 1984. Transfer RNA splicing in Saccharomyces cerevisiae: defining the substrates. Nucleic Acids Res 12: 9367-9382. doi:10.1093/nar/12.24.9367

Ohira T, Suzuki T. 2011. Retrograde nuclear import of tRNA precursors is required for modified base biogenesis in yeast. Proc Natl Acad Sci 108: 10502-10507. doi:10.1073/pnas. 1105645108

Payea MJ, Guy MP, Phizicky EM. 2015. Methodology for the highthroughput identification and characterization of tRNA variants that are substrates for a tRNA decay pathway. Methods Enzymol 560: 1-17. doi:10.1016/bs.mie.2015.03.003

Payea MJ, Sloma MF, Kon Y, Young DL, Guy MP, Zhang X, De Zoysa T, Fields S, Mathews DH, Phizicky EM. 2018. Widespread temperature sensitivity and tRNA decay due to mutations in a yeast tRNA. RNA 24: 410-422. doi:10.1261/rna.064642.117

Peebles CL, Ogden RC, Knapp G, Abelson J. 1979. Splicing of yeast tRNA precursors: a two-stage reaction. Cell 18: 27-35. doi:10 .1016/0092-8674(79)90350-7

Peschek J, Walter P. 2019. tRNA ligase structure reveals kinetic competition between non-conventional mRNA splicing and mRNA decay. Elife 8: e44199. doi:10.7554/eLife.44199

Quartley E, Alexandrov A, Mikucki M, Buckner FS, Hol WG, DeTitta GT, Phizicky EM, Grayhack EJ. 2009. Heterologous expression of L. major proteins in S. cerevisiae: a test of solubility, purity, and gene recoding. J Struct Funct Genomics 10: 233-247. doi:10.1007/s10969-009-9068-9

Ramrath DJ, Lancaster L, Sprink T, Mielke T, Loerke J, Noller HF, Spahn CM. 2013. Visualization of two transfer RNAs trapped in transit during elongation factor G-mediated translocation. Proc Natl Acad Sci 110: 20964-20969. doi:10.1073/pnas.1320387110

Reuter JS, Mathews DH. 2010. RNAstructure: software for RNA secondary structure prediction and analysis. BMC Bioinformatics 11: 129. doi:10.1186/1471-2105-11-129

Rozov A, Demeshkina N, Khusainov I, Westhof E, Yusupov M, Yusupova G. 2016. Novel base-pairing interactions at the tRNA wobble position crucial for accurate reading of the genetic code. Nat Commun 7: 10457. doi:10.1038/ncomms10457

Schmeing TM, Voorhees RM, Kelley AC, Gao YG, Murphy F, Weir JR, Ramakrishnan V. 2009. The crystal structure of the ribosome bound to EF-Tu and aminoacyl-tRNA. Science 326: 688-694. doi:10.1126/science. 1179700

Shaheen HH, Hopper AK. 2005. Retrograde movement of tRNAs from the cytoplasm to the nucleus in Saccharomyces cerevisiae. Proc Natl Acad Sci 102: 11290-11295. doi:10.1073/pnas.0503836102

Shaheen R, Han L, Faqeih E, Ewida N, Alobeid E, Phizicky EM, Alkuraya FS. 2016. A homozygous truncating mutation in PUS3 expands the role of tRNA modification in normal cognition. Hum Genet 135: 707-713. doi:10.1007/s00439-016-1665-7

Sidrauski C, Walter P. 1997. The transmembrane kinase Ire1 $p$ is a sitespecific endonuclease that initiates mRNA splicing in the unfolded protein response. Cell 90: 1031-1039. doi:10.1016/S0092-8674 (00)80369-4

Sidrauski C, Cox JS, Walter P. 1996. tRNA ligase is required for regulated mRNA splicing in the unfolded protein response. Cell 87: 405-413. doi:10.1016/S0092-8674(00)81361-6 
Suzuki T, Nagao A, Suzuki T. 2011. Human mitochondrial tRNAs: biogenesis, function, structural aspects, and diseases. Annu Rev Genet 45: 299-329. doi:10.1146/annurev-genet-110410-132531

Swerdlow H, Guthrie C. 1984. Structure of intron-containing tRNA precursors. Analysis of solution conformation using chemical and enzymatic probes. J Biol Chem 259: 5197-5207.

Takano A, Endo T, Yoshihisa T. 2005. tRNA actively shuttles between the nucleus and cytosol in yeast. Science 309: 140-142. doi:10 $.1126 /$ science. 1113346

Thompson LD, Daniels CJ. 1990. Recognition of exon-intron boundaries by the Halobacterium volcanii tRNA intron endonuclease. $J$ Biol Chem 265: 18104-18111.

Torres AG, Batlle E, de Pouplana L. R. 2014. Role of tRNA modifications in human diseases. Trends Mol Med 20: 306-314. doi:10 .1016/j.molmed.2014.01.008

Trotta CR, Miao F, Arn EA, Stevens SW, Ho CK, Rauhut R, Abelson JN. 1997. The yeast tRNA splicing endonuclease: a tetrameric enzyme with two active site subunits homologous to the archaeal tRNA endonucleases. Cell 89: 849-858. doi:10.1016/S0092-8674(00) 80270-6

Turowski TW, Karkusiewicz I, Kowal J, Boguta M. 2012. Maf1-mediated repression of RNA polymerase III transcription inhibits tRNA degradation via RTD pathway. RNA 18: 1823-1832. doi:10 $.1261 /$ rna.033597.112

Urban A, Behm-Ansmant I, Branlant C, Motorin Y. 2009. RNA sequence and two-dimensional structure features required for efficient substrate modification by the Saccharomyces cerevisiae RNA: $\Psi$-synthase Pus7p. J Biol Chem 284: 5845-5858. doi:10 .1074/jbc.M807986200

Valle M, Zavialov A, Li W, Stagg SM, Sengupta J, Nielsen RC, Nissen P, Harvey SC, Ehrenberg M, Frank J. 2003. Incorporation of aminoacyl-tRNA into the ribosome as seen by cryo-electron microscopy. Nat Struct Biol 10: 899-906. doi:10.1038/nsb1003

Vaňáčová S, Wolf J, Martin G, Blank D, Dettwiler S, Friedlein A, Langen $\mathrm{H}$, Keith G, Keller W. 2005. A new yeast poly(A) polymerase complex involved in RNA quality control. PLoS Biol 3: e189. doi:10.1371/journal.pbio.0030189

Wan Y, Hopper AK. 2018. From powerhouse to processing plant: conserved roles of mitochondrial outer membrane proteins in tRNA splicing. Genes Dev 32: 1309-1314. doi:10.1101/gad.316257 .118

Watanabe K, Miyagawa R, Tomikawa C, Mizuno R, Takahashi A, Hori H, ljiri K. 2013. Degradation of initiator tRNA ${ }^{\text {Met }}$ by $\mathrm{Xrn}_{\mathrm{n}} 1 / 2$ via its accumulation in the nucleus of heat-treated HeLa cells. Nucleic Acids Res 41: 4671-4685. doi:10.1093/nar/gkt153

Westhof E, Dumas P, Moras D. 1985. Crystallographic refinement of yeast aspartic acid transfer RNA. J Mol Biol 184: 119-145. doi:10.1016/0022-2836(85)90048-8
Whipple JM, Lane EA, Chernyakov I, D’Silva S, Phizicky EM. 2011. The yeast rapid tRNA decay pathway primarily monitors the structural integrity of the acceptor and T-stems of mature tRNA. Genes Dev 25: 1173-1184. doi:10.1101/gad.2050711

Xiang S, Cooper-Morgan A, Jiao X, Kiledjian M, Manley JL, Tong L. 2009. Structure and function of the $5^{\prime} \rightarrow 3^{\prime}$ exoribonuclease Rat1 and its activating partner Rai1. Nature 458: 784-788. doi:10 .1038/nature07731

Xue Y, Bai X, Lee I, Kallstrom G, Ho J, Brown J, Stevens A, Johnson AW. 2000. Saccharomyces cerevisiae RAl1 (YGL246c) is homologous to human DOM3Z and encodes a protein that binds the nuclear exoribonuclease Rat1p. Mol Cell Biol 20: 4006-4015. doi:10.1128/MCB.20.11.4006-4015.2000

Xue S, Calvin K, Li H. 2006. RNA recognition and cleavage by a splicing endonuclease. Science 312: 906-910. doi:10.1126/science .1126629

Yarham JW, Elson JL, Blakely EL, McFarland R, Taylor RW. 2010. Mitochondrial tRNA mutations and disease. WIRES RNA 1: 304324. doi:10.1002/wrna.27

Yarham JW, Lamichhane TN, Pyle A, Mattijssen S, Baruffini E, Bruni F, Donnini C, Vassilev A, He L, Blakely EL, et al. 2014. Defective i6A37 modification of mitochondrial and cytosolic tRNAs results from pathogenic mutations in TRIT1 and its substrate tRNA. PLoS Genet 10: e1004424. doi:10.1371/journal.pgen .1004424

Yoo CJ, Wolin SL. 1997. The yeast La protein is required for the $3^{\prime}$ endonucleolytic cleavage that matures tRNA precursors. Cell 89: 393-402. doi:10.1016/S0092-8674(00)80220-2

Yoshihisa T, Yunoki-Esaki K, Ohshima C, Tanaka N, Endo T. 2003. Possibility of cytoplasmic pre-tRNA splicing: the yeast tRNA splicing endonuclease mainly localizes on the mitochondria. Mol Biol Cell 14: 3266-3279. doi:10.1091/mbc.e02-11-0757

Yoshihisa T, Ohshima C, Yunoki-Esaki K, Endo T. 2007. Cytoplasmic splicing of tRNA in Saccharomyces cerevisiae. Genes Cells 12: 285-297. doi:10.1111/j.1365-2443.2007.01056.x

Yun JS, Yoon JH, Choi YJ, Son YJ, Kim S, Tong L, Chang JH. 2018. Molecular mechanism for the inhibition of DXO by adenosine 3',5'-bisphosphate. Biochem Biophys Res Commun 504: 89-95. doi:10.1016/j.bbrc.2018.08.135

Zhou J, Lancaster L, Donohue JP, Noller HF. 2013. Crystal structures of EF-G-ribosome complexes trapped in intermediate states of translocation. Science 340: 1236086. doi:10.1126/science .1236086

Zhou J, Lancaster L, Donohue JP, Noller HF. 2014. How the ribosome hands the A-site tRNA to the P site during EF-G-catalyzed translocation. Science 345: 1188-1191. doi:10.1126/science .1255030 

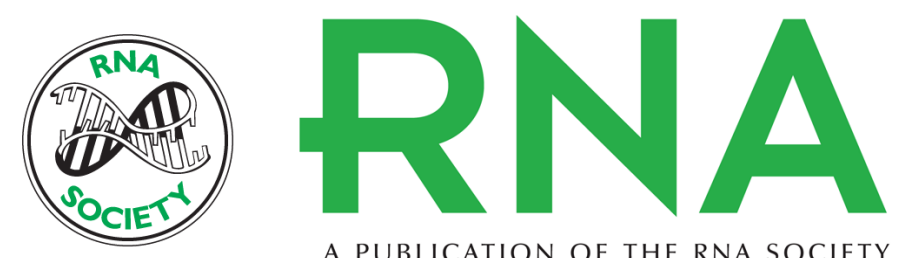

A PUBLICATION OF THE RNA SOCIETY

\title{
Mutations in the anticodon stem of tRNA cause accumulation and Met22-dependent decay of pre-tRNA in yeast
}

\author{
Matthew J. Payea, Alayna C. Hauke, Thareendra De Zoysa, et al.
}

RNA 2020 26: 29-43 originally published online October 16, 2019

Access the most recent version at doi:10.1261/rna.073155.119

\section{Supplemental http://rnajournal.cshlp.org/content/suppl/2019/10/16/rna.073155.119.DC1 Material}

References This article cites 91 articles, 39 of which can be accessed free at: http://rnajournal.cshlp.org/content/26/1/29.full.html\#ref-list-1

Creative This article is distributed exclusively by the RNA Society for the first 12 months after the Commons License full-issue publication date (see http://rnajournal.cshlp.org/site/misc/terms.xhtml). After 12 months, it is available under a Creative Commons License (Attribution-NonCommercial 4.0 International), as described at http://creativecommons.org/licenses/by-nc/4.0/.
Email Alerting Receive free email alerts when new articles cite this article - sign up in the box at the Service top right corner of the article or click here.

\section{|||||||| Providing Precise Solutions for your research.}

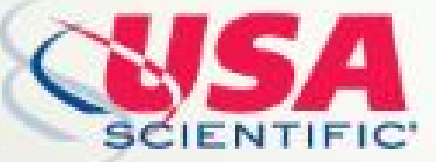

To subscribe to $R N A$ go to:

http://rnajournal.cshlp.org/subscriptions 